Running head: MULTI-DIMENSIONAL IDEOLOGY AND PREJUDICE

\title{
Social and Economic Ideologies Differentially Predict Prejudice across the Political Spectrum, but Social Issues are Most Divisive
}

\author{
Jarret T. Crawford \\ The College of New Jersey \\ Mark J. Brandt \\ Tilburg University \\ Yoel Inbar \\ University of Toronto \\ John R. Chambers \\ University of Central Florida \\ Matt Motyl \\ University of Illinois at Chicago
}

Paper Accepted at Journal of Personality and Social Psychology. Please cite as:

Crawford, J. T., Brandt, M. J., Inbar, Y., Chambers, J. R., \& Motyl, M. (2017). Social and economic ideologies differentially predict prejudice across the political spectrum, but social issues are most divisive. Journal of Personality and Social Psychology, 112, 383412.

Corresponding author: Jarret T. Crawford, Psychology Department, The College of New Jersey, 2000 Pennington Rd., Ewing, NJ 08628. Email: crawford@tcnj.edu

Acknowledgements: We thank the YourMorals team for collecting and providing the data used in Study 1 (Sample 1). Portions of that data were previously published in Koleva, Graham, Iyer, Ditto, \& Haidt, 2012. We also thank the members of The College of New Jersey's Political Psychology Lab and students enrolled in the corresponding author's Research Seminar course for their assistance with data collection for Study 4. 


\begin{abstract}
Liberals and conservatives both express prejudice toward ideologically dissimilar others (Brandt et al., 2014). Previous work on ideological prejudice did not take advantage of evidence showing that ideology is multi-dimensional, with social and economic ideologies representing related but separable belief systems. In five studies (total $N=4912$ ), we test three competing hypotheses of a multi-dimensional account of ideological prejudice. The dimension-specific symmetry hypothesis predicts that social and economic ideologies differentially predict prejudice against targets who are perceived to vary on the social and economic political dimensions, respectively. The social primacy hypothesis predicts that such ideological worldview conflict is experienced more strongly along the social than economic dimension. The social-specific asymmetry hypothesis predicts that social conservatives will be more prejudiced than social liberals, with no specific hypotheses for the economic dimension. Using multiple target groups, multiple prejudice measures (e.g., global evaluations, behavior), and multiple social and economic ideology measures (self-placement, issue positions), we found relatively consistent support for the dimension-specific symmetry and social primacy hypotheses, and no support for the socialspecific asymmetry hypothesis. These results suggest that worldview conflict and negative intergroup attitudes and behaviors are dimension-specific, but that the social dimension appears to inspire more political conflict than the economic dimension.
\end{abstract}




\section{Social and Economic Ideologies Differentially Predict Prejudice across the Political Spectrum, but Social Issues are Most Divisive}

Right-wing political ideologies have long been associated with prejudice, stereotyping, and discrimination in the social, personality, and political psychology literatures (Allport, 1954; Sibley \& Duckitt, 2008), suggesting a "prejudice gap" between conservatives and liberals (Chambers, Schlenker, \& Collisson, 2013). Right-wing ideologies-right-wing authoritarianism (Altemeyer, 1998), social dominance orientation (Sidanius \& Pratto, 1999), and systemjustifying meritocratic beliefs (Jost \& Thompson, 2000), as well as conservative selfidentification or issue positions (e.g., Terrizzi, Shook, \& Ventis, 2010)—predict prejudice toward several groups, including ethnic minorities (Brandt \& Reyna, 2014), sexual minorities (Crawford, Brandt, Inbar, \& Mallinas, 2016; Terrizzi et al., 2010), immigrants (Hodson, Hogg, \& MacInnis, 2009), and women (Sibley, Wilson, \& Duckitt, 2007). Meta-analytic evidence (Sibley \& Duckitt, 2008) suggests strong influences of right-wing political ideologies (i.e., RWA and $\mathrm{SDO}, r \mathrm{~s}=.49$ and .55 , respectively) on an assortment of group prejudices.

However, new research has called the so-called "prejudice gap" into question. Research on the ideology-prejudice relationship was largely limited to examining prejudice against low status, disadvantaged social groups—groups that tend to be left-wing themselves, or emblematic of left-wing causes in the United States (e.g., African-Americans, atheists, gay men and lesbians). This suggests that left-wing ideology might be associated with prejudice against groups that are right-wing or emblematic of right-wing causes. Consistent with this prediction, when the political ideology of targets of prejudice are varied (e.g., pro-life and pro-choice activists; atheists and Evangelical Christians) conservatism does not predict prejudice per se. Rather, the effects of political ideology on prejudice are moderated by the target's political orientation, such 
that conservatism predicts prejudice against more left-wing targets, whereas liberalism predicts prejudice against more right-wing targets (Chambers et al., 2013; Crawford \& Pilanski, 2014; Wetherell, Brandt, \& Reyna, 2013). Effect sizes for liberals’ and conservatives’ prejudices are roughly equal.

Summarizing this evidence, Brandt and colleagues (2014) developed the ideological conflict hypothesis, which posits that people from across the political spectrum are willing to express prejudice toward ideologically dissimilar others because such targets hold conflicting worldviews that threaten deeply held values and moral beliefs. Subsequent research has found that liberals' and conservatives' prejudices manifest to roughly equal degrees across a variety of prejudice measures, including feeling thermometer/warm-cold ratings, social distance ratings, political intolerance (i.e., denial of rights), hiring decisions, emotion ratings, and resource allocation in economic (i.e., dictator) games (Crawford, Inbar, \& Maloney, 2014; Crawford, Kay, \& Duke, 2015; Crawford, Mallinas, \& Furman, 2015; Gift \& Gift, 2015; Iyengar \& Westwood, 2014; van Prooijen, Krouwel, Boiten, Eendebak, 2015; Waytz, Young, \& Ginges, 2014). Further, worldview conflict (e.g., symbolic threat; perceived value dissimilarity) underlies prejudice on both the political left and right (Crawford, 2014; Wetherell et al., 2013). This may be surprising given the openness to experience typically reported by political liberals (Jost, Glaser, Kruglanski, \& Sulloway, 2003; Sibley \& Duckitt, 2008); however, even people open to experience express prejudice towards people that do not share their beliefs (Brandt, Chambers, Crawford, Wetherell, \& Reyna, 2015). While evidence for the ideological conflict hypothesis is inconsistent with the prejudice gap findings, it is consistent with evidence that people are generally more tolerant of similar than dissimilar others (Byrne, 1971; van Osch \& Breugelmans, 2012).

\section{Defining Prejudice}


We adopt standard approaches to conceptualizing and operationalizing prejudice and apply them to groups across the political spectrum. Our approach follows well-established definitions of prejudice as negative affect/feelings and recognizes that prejudice can be expressed towards (and by) any social group (Brown, 2010; Crandall, Eshleman, \& O’Brien, 2002). Using a large range of target groups, from typical targets (e.g., low status ethnic groups) to atypical targets (e.g., high status, advantaged groups), is unusual in social psychology. However, it is consistent with established definitions of prejudice that define prejudice by its negative affect and not by the characteristics of its specific target (e.g., "Prejudice is a two-way street; it often flows from the minority group to the majority group as well as in the other direction. And any group can be a target of prejudice;" emphasis ours; Aronson, Wilson, \& Akert, 2010, p. 388).

Our studies include typical targets of prejudice as well as less studied target groups. This strategy is theoretically useful because it helps identify effects of ideology on prejudice that are consistent across many target groups, and to see how the effects differ depending on target group characteristics. However, given the strength of the moral approbation commonly associated with the term "prejudice," we also want to highlight that studying prejudice towards many target groups says nothing about the morality or appropriateness of expressing prejudice towards these groups.

\section{Unidimensional vs. Multidimensional Accounts of Political Ideology}

Researchers primarily characterize political ideology with a single dimension that spans from "liberal" or "left-wing" on one hand and "conservative" or "right-wing" on the other (e.g., Jost et al., 2003; Jost, 2006; Jost, Nosek, \& Gosling, 2008). This perspective has effectively highlighted the predictive power of a unitary dimension (e.g., in U.S. elections; Jost, 2006), and is the basis for highly influential theories of ideology. For example, the motivated social 
cognition perspective (e.g., Jost et al., 2003) argues that whereas different types of ideological belief systems (such as social and economic ideologies) might be distinct in their policy-based outcomes, they have shared antecedents of needs for certainty and security (Hibbing, Smith, \& Alford, 2014; Jost et al., 2003). That said, although research shows that a unidimensional account can capture important variance in political beliefs, it omits much complexity. Evidence that falsifies the unidimensional account comes in at least three forms.

First, the extensive literature on abstract values consistently finds more than one dimension of values. Rokeach (1973) found dimensions of freedom and equality, and Schwartz (1992) found dimensions spanning the continua from "openness to change to conservation" and "self-enhancement to self-transcendence". Both dimensions appear relevant to politics (Schwartz, Caprara \& Vecchione, 2010). Second, right-wing authoritarianism (RWA; or traditionalism) and social dominance orientation (SDO; or anti-egalitarianism) are correlated but independent dimensions of political attitudes (Duckitt \& Sibley, 2010; Schwartz et al., 2010). This distinction is the basis for the dual process motivational model of prejudice (DPM; Sibley \& Duckitt, 2008), which predicts that these two sets of political attitudes will have different antecedents and consequences. Consistent with this, RWA and SDO are correlated with different motivations (Sibley, Wilson, \& Duckitt, 2007) and personality traits (Duckitt \& Sibley, 2010), and are affected by different types of experimental manipulations (Duckitt \& Fisher, 2003).

Third, political issues and attitudes fall along multiple dimensions. Saucier (2000) sampled over 200 social attitudes (so-called -isms) and found three attitude dimensions. Others have examined the dimensions of political attitudes more specifically. Using factor analytic and dimensional scaling techniques, the data clearly shows more than one dimension of political attitudes (e.g., Carmines, Ensley, \& Wagner, 2012; Feldman \& Johnston, 2014; Johnston \& 
Wronski, 2015; Malka, Soto, Inzlicht, \& Lelkes, 2014; for reviews see Carmines \& D’Amico, 2015; Malka \& Soto, 2015). Distinguishing between multiple dimensions is consequential for the conclusions we draw about political attitudes because the different dimensions have different associations with values (Malka et al., 2014) and personality traits (Feldman \& Johnston, 2014).

In this paper, we build on the above work (e.g., Carmines \& D’Amico, 2015; Malka et al., 2014) that distinguishes between social ideologies and economic ideologies in order to understand ideological conflict. Social ideologies emphasize traditional moral and cultural issues (with conservatives and liberals favoring greater vs. lesser restriction, respectively, on personal freedom in moral and cultural domains). Economic ideologies emphasize the role of the government in regulating the economy (with conservatives and liberals favoring lesser vs. greater roles for the government in regulating the economy, respectively). Although social and economic orientations often go hand-in-hand in the United Sates ( $r s=.21$ and .36 in 2000 and 20004 nationally representative samples; Feldman \& Johnston, 2014), they are substantially less correlated in other regions ( $r=-.08$ in a sample of 51 countries; Malka et al., 2014).

\section{A Multi-Dimensional Account of Ideological Conflict}

\section{Dimension-Specific Symmetry Hypothesis}

The ideological conflict hypothesis (Brandt et al., 2014) predicts that people are hostile to those with conflicting worldviews. This work has used unidimensional measures of ideology (e.g., Chambers et al., 2013) or collapsed social and economic dimensions into one predictor (i.e., Wetherell, Brandt, \& Reyna, 2013). However, the above reviewed evidence suggests that people's perceptions of worldview conflict may also be dimension-specific. That is, people perceive conflict between their own social and economic beliefs and those of others, and that dimension-specific worldview conflict fuels negative intergroup attitudes. Figure 1 Panel A 
captures the essential predictions that derive from this dimension-specific symmetry hypothesis. Specifically:

- $\quad$ social (but not economic) conservatism should predict prejudice against socially liberal targets (e.g., atheists)

- $\quad$ social (but not economic) liberalism should predict prejudice against socially conservative targets (e.g., Evangelical Christians)

- economic (but not social) conservatism should predict prejudice against economically liberal targets (e.g., welfare recipients)

- economic (but not social) liberalism should predict prejudice against economically conservative targets (e.g., investment bankers).

Other research has examined the multidimensionality of prejudice. The dual process model of prejudice (Duckitt \& Sibley, 2010) predicts that because RWA and SDO have distinct personality and motivational underpinnings (mentioned above), they will predict prejudice against different types of target groups. Specifically, RWA predicts prejudice against groups who threaten societal cohesion, whereas SDO predicts prejudice against low-status groups who threaten existing status hierarchies (Duckitt \& Sibley, 2007).

Our multi-dimensional approach to ideological conflict is consistent with the dual process model in that it recognizes the impact of two related but distinct ideological dimensions on intergroup attitudes. Where it diverges from the dual process model is that the dual process model does not account for prejudice across the political spectrum. Rather, it seeks to understand prejudice directed toward socially disadvantaged, low status, and deviant target groups (who tend to be left-wing) among people who hold right-wing ideologies. In Sibley and Duckitt's (2008) meta-analysis of the relationship between right-wing ideologies (i.e., RWA and SDO) and 
prejudice, prejudice is primarily operationalized as negative attitudes toward ethnic minorities, women, or other historically disadvantaged groups (e.g., homosexuals, the disabled; see also Duckitt \& Sibley, 2007). By examining prejudice against targets from across the political spectrum, our multi-dimensional approach can provide a fuller account of prejudice, one that posits (dimension-specific) ideological conflict, rather than particular right-wing ideologies, as one potential mechanism driving prejudice.

\section{Alternative Hypotheses}

Prior findings point to the possibility that ideological conflict may be felt (and expressed) more robustly along the social dimension compared to the economic dimension of political ideology. We aim to test two hypotheses based on this idea.

Social Primacy Hypothesis. The social primacy hypothesis predicts that both social and economic dimensions of ideology will predict ideological conflict, but that the effects of the social dimension will be larger than the effects of the economic dimension. This hypothesis is depicted in Figure 1 Panel B. There are several pieces of evidence in favor of this hypothesis. Social attitudes are more important in determining people's political identities, such that people's political self-identification as liberal or conservative is more strongly determined by their positions on social than on economic issues (Feldman \& Johnston, 2014) and personal values more strongly underlie positions on social than on economic issues (Malka et al., 2014). Indeed, the rise of conflict over social and cultural issues are a primary contributor to political polarization, at least among elites (Hare \& Poole, 2014). Among the public, the most divisive moral foundations are those most relevant to social attitudes (authority and purity/sanctity; Graham, Haidt, \& Nosek, 2009; Koleva, Graham, Iyer, Ditto, \& Haidt, 2012). The importance of 
the social dimension for ideological conflict is historically recent, as up until the last two decades there was relative agreement on social issues in the United States (Ellis \& Stimson, 2012).

Work on "hard" and "easy" political issues also suggests that social issues will be the most divisive. Social issues are often considered easy issues that are non-technical and possess symbolic value for political experts and non-experts alike. Economic issues, however, are often considered hard issues that are more technical and require greater political sophistication to grasp their implications (Carmines \& Stimson, 1980; Johnston \& Wronski, 2015). Thus, social issues may elicit more gut-level, negative reactions among a greater variety of people than would economic issues. Together, these prior findings point to the possibility that the social dimension of ideology will show stronger ideological conflict effects than the economic dimension.

Social-Specific Asymmetry Hypothesis. The social-specific asymmetry hypothesis predicts that social conservatives will express prejudice, but social liberals will not. This hypothesis, depicted in Figure 1 Panel $\mathrm{C}$, is derived from research showing that needs for closure and certainty are more strongly and consistently related to social conservatism (Feldman \& Johnston, 2014; Malka et al., 2014; van Hiel, Pandelaere, \& Duriez, 2004) along with evidence that needs for closure and certainty are often linked with prejudice and intolerance (Roets \& van Hiel, 2011). Accordingly, people with socially conservative views, who typically have higher needs for closer and certainty, should express prejudice towards ideologically dissimilar others. People with socially liberal views, who typically have lower needs for closure and certainty, should express more tolerance. The social-specific asymmetry hypothesis therefore predicts that social conservatives will appear most consistent with perspectives that predict more prejudice among conservatives than among liberals (e.g., Sibley \& Duckitt, 2008; Terrizzi et al., 2010). Because some evidence suggests that needs for closure are unrelated to (van Hiel et al., 2004) or 
even negatively related to economic conservatism (Malka et al., 2014), the social-specific asymmetry hypothesis is agnostic regarding the economic dimension.

\section{The Present Studies}

We tested these three hypotheses in five studies. Although each hypothesis has different implications for how we understand ideology and prejudice, support for any of them suggests that a unidimensional approach is incomplete. Across studies, we used both within-subject and between-subject designs, multiple measures of prejudice (e.g., social distance, dictator game, IAT), and multiple measures of ideology (e.g., self-identification, issue positions) to triangulate on the three hypotheses.

For the dimension-specific symmetry hypothesis, full support means that all relevant paths were significant on all relevant outcome variables, whereas mixed support means that some but not all predicted effects were significant or that there was support on some but not all outcome variables, but that the pattern of results fit the hypotheses. For the social primacy hypothesis, full support means that it was supported by the formal analyses of that hypothesis, whereas mixed support means that it wasn't supported by the formal analyses, but the Social Ideology $\times$ Orientation $\times$ Dimension interaction was significant while the Economic Ideology $\times$ Orientation $\times$ Dimension was not. Full support for the social-specific asymmetry hypothesis means that biases emerged among social conservatives but not social liberals, whereas mixed support means that biases emerged among both, but were larger among social conservatives.

\section{Study 1}

Study 1 used three samples of Americans to test the three hypotheses of multidimensional ideological conflict. In each sample, participants completed separate single-item measures of their social and economic ideological self-identifications, along with warmth ratings 
of a variety of target groups spanning the ideological spectrum (78 total across all three samples). In a fourth online sample, we measured the perceived social and economic political orientation of each of these targets, and aggregated these perceived ideology ratings of the targets to examine whether the differential effects of social and economic political ideologies on prejudice are moderated by the targets' perceived social and economic ideology, respectively.

\section{Method}

Sample 1 consisted of 3300 U.S. residents $\left(58 \%\right.$ Male, $\left.M_{\text {age }}=39.46\right)$ who volunteered at www.yourmorals.org. Participants had previously registered with the website and were given the option to choose from among several available surveys. Results reported here are from the Social Groups Survey. Participants rated 48 social targets on a 7-point perceived warmth scale [1= Very cold (unfavorable), 7 = Very warm (favorable)]. Target order was randomized. Participants' social and economic political ideologies were assessed on separate 7-point items (“In general, how liberal (left-wing) or conservative (right-wing) are you on social [economic] issues?"; 1 = Very liberal , 7 = Very conservative, $8=$ Don't know, $9=$ Can't pick one label). Participants indicating “don't' know” or “can't pick one label” were excluded from these analyses.

Samples 2 and 3 were collected through Amazon.com's Mechanical Turk (MTurk), and comprised $236\left(74 \%\right.$ White; 64\% female; $M_{\text {age }}=36.97$ years $)$ and 203 (58\% White; 54\% male; $M_{\text {age }}=32.20$ years) U.S. residents, respectively, who were compensated 50 cents for their participation. Recent research indicates that MTurk is a valid platform for conducting research on political ideology (Clifford, Jewell, \& Waggoner, 2015), and that MTurk results are comparable to those drawn from nationally representative samples (Brandt \& van Tongeren, in press). Participants first provided perceived warmth ratings on $0-100$ scales for 18 (Sample 2) 
and 39 (Sample 3) targets, with 41 unique targets across Samples 2 and 3. Target order was randomized. Targets were chosen from a variety of sources assessing attitudes towards a host of social groups (Cuddy, Fiske, \& Glick, 2007; Crawford \& Pilanski, 2014; Duckitt \& Sibley, 2008; Fiske, Cuddy, Glick, \& Xu, 2002). After providing target warmth ratings, we assessed participants' social and economic political ideologies using separate 7-point items ('In terms of social [economic] policy, where would you place yourself on this scale?"; 1 = Extremely liberal; 7 = Extremely conservative). Demographic information (e.g., age, race/ethnicity, gender) was collected at the end of each MTurk survey.

Targets were not pre-selected for their potential relevance to social and economic political ideology in any of the three samples. In all three samples, warmth ratings were recoded so that higher scores reflect more prejudice.

To determine the perceived social and economic ideology of the 78 unique targets included across Samples 1 - 3, we collected an additional sample of 151 U.S. residents (sample 4; $67 \%$ White; $57 \%$ Male; $M_{\text {age }}=33.80$ years) through MTurk. Participants evaluated each of the 78 targets for their perceived social and economic ideology on separate 7-point items ("In terms of social [economic] policy, where would you place each of the following groups on this scale?"; $1=$ Extremely liberal, $7=$ Extremely conservative . The order of the social and economic ideology assessments was randomized, and the order of targets within each assessment was also randomized. The intraclass correlation coefficients for perceived social and economic ideology were both $I C C=.80$.

\section{Results}


The perceived social and economic ideology ratings of each target, and the associations of social and economic ideologies with prejudice against each target, are presented in Tables S1S3 in Supplemental Online Materials (SOM).

\section{Primary Analyses}

We tested our hypotheses using multilevel models with the MIXED command in SPSS version 21. Participants' social and economic ideologies (Social Orientation, Economic Orientation) were treated as between-subjects variables, and the mean perceived social and economic ideology ratings from Sample 4 (Social Perceived, Economic Perceived) were treated as within-subjects variables (for a similar strategy see Brandt et al., 2015). Participant social and economic ideologies and perceived social and economic ideologies were midpoint-centered (i.e., centered on moderates) and entered in the model. The intercept and the slopes for perceived social and economic ideologies were specified as random effects.

The three hypotheses each predict a Social Orientation $\times$ Social Perceived interaction. The dimension-specific hypothesis predicts an Economic Orientation $\times$ Economic Perceived interaction similar in size to the Social Orientation $\times$ Social Perceived interaction. The social primacy hypothesis predicts that the Social Orientation $\times$ Perceived Social interaction will be stronger than the Economic Orientation $\times$ Perceived Economic interaction. The social-specific asymmetry hypothesis predicts that the Social Orientation $\times$ Perceived Social interaction will be a spreading interaction, such that social conservatives but not liberals express prejudice towards the ideologically dissimilar group.

Model results for all three samples are reported in Table 1. For space considerations, we only present slopes from Sample 1 in the main text; slopes for Samples $1-3$ are reported in Table S4 in SOM. Figure 2 displays results from Sample 1; Figures S1 and S2 (in SOM) display 
those from Samples 2 and 3, respectively. The Social Orientation $\times$ Perceived Social and the Economic Orientation $\times$ Perceived Economic interactions were significant. Unexpectedly, the Social Orientation $\times$ Perceived Economic and the Economic Orientation $\times$ Perceived Social interactions were also significant. ${ }^{1,2}$ All interactions were probed at \pm 1 SD the midpoint of each of the four variables. ${ }^{3}$

When looking at the social dimension, we find support for the dimension-specific symmetry hypothesis. Among socially conservative participants in Sample 1, greater perceived social conservatism was associated with less prejudice $(b=-1.27, S E=.05, p<.001)$. However, this effect did not replicate in Samples 2 or 3, although the effects of perceived social ideology were in the expected direction. Among socially liberal participants in all three samples, greater perceived social conservatism was associated with greater prejudice (Sample 1: $b=.33, S E=$ $.02, p<.001)$

When looking at the economic dimension, we also found support for the dimensionspecific symmetry hypothesis. Among economically conservative participants in all three samples, greater perceived economic conservatism was associated with less prejudice (Sample 1: $b=-.59, S E=.03, p<.001)$. Among economically liberal participants, greater perceived economic conservatism was associated with greater prejudice in all samples except Sample 2, in

\footnotetext{
${ }^{1}$ We also probed the effects for the unexpected interactions, but do not discuss them because of space. They are in Table S4. The effects of the non-predicted ideological dimension on prejudice were in the opposite direction of the predicted effects (e.g., the effect of perceived social conservatism on prejudice among socially liberal participants), rather than being non-significant. This likely reflects suppression effects due to multicollinearity between either participant social and economic ideology $(r \mathrm{~s}=.52, .55$, and .71 in Samples $1-3$, respectively) or the aggregate mean perceptions of social and economic ideology $(r=.50$, Sample 4$)$. While multicollinearity can often pose a problem with data interpretation, testing the differential effects of social and economic ideology on prejudice requires retaining both measures in models testing the hypotheses (see the dual process model literature for similar approaches; e.g., Duckitt \& Sibley, 2010). The remaining studies do not have the same limitation.

${ }^{2}$ All effects remained significant when controlling for interactions with demographic covariates in Samples 1 (age, gender, education, SES) and Samples 2 and 3 (age, gender, ethnicity, education, SES).

${ }^{3}$ Note that in some cases, the estimates in these figures fall outside of the range of scores, and thus such estimates should be interpreted with caution.
} 
which perceived economic conservatism was unrelated to prejudice (Sample 1: $b=1.34, S E=$ $.05, p<.001)$

Table 1 reveals that support for the social primacy hypothesis cannot be found in Samples 1 or 2 , as the unstandardized regression coefficients for the Social Orientation $\times$ Perceived Social interactions ( $b s=-.41$ and -8.93 , respectively) are smaller than those for the Economic Orientation $\times$ Perceived Economic interaction $(b s=-.47$ and -11.34 , respectively). In Sample 3, the Social Orientation $\times$ Perceived Social interaction coefficient $(b=-6.89)$ appears nominally larger than the Economic Orientation $\times$ Perceived Economic interaction coefficient $(b=-5.96)$. To formally test the social primacy hypothesis in Sample 3, using Mplus version 7 software (Muthén \& Muthén, 2008-2012), we compared the size of the Akaike information criteria (AIC) and Bayesian information criteria (BIC) for a model in which the Social Orientation $\times$ Perceived Social and Economic Orientation $\times$ Perceived Economic interaction coefficients were constrained to be equal against a model in which these interactions were not constrained to be equal. The AIC and BIC were smaller in the constrained (72671.15 and 72775.68, respectively) than in the unconstrained model (72672.15 and 72783.64, respectively), indicating that the constrained model had better fit, and thus, the two coefficients were statistically equal. Thus, Study 1 reveals no support for the social primacy hypothesis.

Table S4, along with Figure 1 and Figures S1 and S2, show that there was no support for the social-specific asymmetry hypothesis in these three samples; socially conservative participants never expressed more prejudice than did socially liberal participants. If anything, there was less bias among socially conservative than socially liberal participants in these samples.

\section{Discussion}


Study 1's findings provide initial evidence that ideological conflict is dimension-specific. Although there was some variation in support for these predictions in Samples 2 and 3, these samples were much smaller than Sample 1. There was no support for the social primacy or social-specific asymmetry hypotheses in these three samples.

\section{Study 2}

Although Study 1's examination of multiple groups across multiple samples was advantageous, it suffered two primary limitations: 1) worldview conflict, one of the primary motivators of ideology-based prejudice (Brandt et al., 2014), was only measured indirectly; and 2) it relied on one single measure of prejudice (i.e., warmth or feeling thermometer ratings). Study 2 addressed these limitations by asking participants to evaluate a single target group that varied in its ideological orientation (liberal vs. conservative) and dimension (social vs. economic), directly measuring worldview conflict, and including a measure of behavioral intention (i.e., social distance) in addition to an affective measure (i.e. feeling thermometer) to assess prejudice.

\section{Method}

\section{Participants}

Two hundred fifty participants (38\% female; $77 \%$ White; $M_{\text {age }}=30$ years $)$ were recruited through MTurk.

\section{Materials and Procedure}

Participants were randomly assigned to a target group in a 2 (Orientation: liberal, conservative $) \times 2$ (Dimension: social, economic) between-subjects design, resulting in a socially conservative (Evangelical Christians, $N=62$ ), socially liberal (atheists, $N=62$ ), economically conservative (wealthy businesspeople, $N=63$ ) or economically liberal (poor people on welfare, 
$N=63$ ) target group. These targets were chosen because they were clearly perceived as higher in one dimension than the other on the basis of the average perceived social and economic ideologies in Study 1 (all differences in the mean ratings were greater than .28 on a 1-7 scale; see Column 3 in Tables S1 and S2), and because the targets on the same dimension seemed to possess opposing social or political beliefs (e.g., atheists vs. Evangelical Christians on the social dimension). Participants completed the following assessments of their assigned group, in random order:

1. A feeling thermometer rating $(0=$ Very cold, $100=$ Very warm; reverse-scored $)$.

2. A 7-item social distance measure, completed with the stem, "I would be happy to have [group]": as a neighbor, as a coworker, as a roommate, marry into my family, as someone I would personally date, as a close personal friend, as a dinner guest in my home $(1$ = Strongly disagree $; 7$ Strongly agree $)$. Items were reverse-scored so that higher values indicated more distancing, and were averaged to form the social distance measure $(\alpha=.96)$. The feeling thermometer and social distance measures were highly correlated with each other $(r=.78)$; we therefore rescaled each measure to a $0-1$ scale and averaged across them to create a single prejudice outcome variable.

3. A single item measuring worldview conflict ("Please indicate the extent to which you see [group] as holding political or social beliefs different from your own"; $1=$ Not at all different from me; 7 = Very different from me; see Brandt et al., 2015).

Participants then completed the same single-item measures of social and economic ideology included in Study 1 (Samples 1 \& 2), political party identification, and demographic 
information including age, gender, race/ethnicity, religious affiliation, religiosity, education, and socioeconomic status.

\section{Results}

Table S5 reports the correlations among and $M$ s and $S D$ s for social ideology, economic ideology, worldview conflict, and prejudice.

\section{Primary Analyses}

The key hypothesis tests in this 2 (Orientation: liberal, conservative) $\times 2$ (Dimension: social, economic) $\times$ continuous $($ Social Ideology $) \times$ continuous $($ Economic Ideology) design are the Social Ideology $\times$ Orientation $\times$ Dimension and Economic Ideology $\times$ Orientation $\times$ Dimension interactions. All three hypotheses predict the social ideology three-way interaction. The dimension-specific hypothesis also predicts that both interactions will be similar in size. The social primacy hypothesis predicts that the social ideology three-way interaction will be stronger than economic ideology three-way interaction. The social-specific asymmetry hypothesis predicts that the social ideology three-way interaction will be a spreading interaction, such that only social conservatives express prejudice towards the ideologically dissimilar group.

We performed moderated multiple regression analyses on the outcome variables. In each model, Social Ideology (midpoint-centered), Economic Ideology (midpoint-centered), Orientation $(0=$ left-wing, $1=$ right-wing $)$, and Dimension $(0=$ social, $1=$ economic $)$ were entered in Step 1, all two-way interactions in Step 2, and all three-way interactions in Step 3 (Aiken \& West, 1991). ${ }^{4}$ Table 2 reports Step 3 of the moderated multiple regression analyses for both worldview conflict and prejudice (full models are reported in Tables S6 and S7 in SOM).

\footnotetext{
${ }^{4}$ Results from these analyses were largely unchanged after accounting for interactions with demographic covariates (age, gender, ethnicity, education, and SES), although the Economic Ideology $\times$ Orientation $\times$ Dimension interaction on worldview conflict was reduced from marginal significance to non-significance with covariate inclusions ( $p$ s < $.20)$.
} 
Worldview conflict. There was a significant Social Ideology $\times$ Orientation $\times$ Dimension interaction, and a marginally significant Economic Ideology $\times$ Orientation $\times$ Dimension interaction $(p=.088)$, which were in opposite directions of each other.

Figure $3 \mathrm{~A}$ and $3 \mathrm{~B}$ displays the Social Ideology $\times$ Orientation $\times$ Dimension interaction. As expected, Social Ideology positively predicted worldview conflict regarding atheists and negatively predicted worldview conflict regarding Evangelical Christians, while it was unrelated to worldview conflict regarding either businesspeople or welfare recipients. Looked at another way, social conservatives (+1 SD) saw greater worldview conflict with atheists than with Evangelical Christians $(b=-1.63, S E=.60,95 \%$ CIs $[-2.81,-.44], t=-2.71, p=.007)$, and social liberals (-1 SD) saw greater worldview conflict with Evangelicals than with atheists $(b=2.75$, $S E=.35,95 \%$ CIs $[2.06,3.45], t=7.80, p<.001)$. Social liberals and conservatives both saw greater worldview conflict with businesspeople than with welfare recipients $(p s<.089)$.

Figure $3 \mathrm{C}$ and $3 \mathrm{D}$ display the Economic Ideology $\times$ Orientation $\times$ Dimension interaction. Economic Ideology was positively related to worldview conflict regarding welfare recipients, but not significantly so $(p=.159)$. It was negatively related to worldview conflict regarding businesspeople. As expected, Economic Ideology was unrelated to worldview conflict regarding Evangelical Christians or atheists. Looked at another way, although economic conservatives $(+1$ SD) did not see more worldview conflict with one group that varied by economic dimension than the other $(b=-.32, S E=.51,95 \%$ CIs $[-1.32, .69], t=-.63, p=.531)$, economic liberals $(-1 \mathrm{SD})$ saw greater worldview conflict with businesspeople than with welfare recipients $(b=2.42, S E=$ $.74,95 \%$ CIs $[.97,3.87], t=3.28, p<.001)$. Economic liberals and conservatives did not see significantly more worldview conflict with one social target than the other $(p s>.091)$. 
Prejudice. There was a significant Social Ideology $\times$ Orientation $\times$ Dimension interaction; although the Economic Ideology $\times$ Orientation $\times$ Dimension interaction was in the expected direction, it was not significant $(p=.288)$.

Figure 4A and 4B display the Social Ideology $\times$ Orientation $\times$ Dimension interaction. Social Ideology positively predicted prejudice against atheists and negatively predicted prejudice against Evangelical Christians, while it was unrelated to prejudice against businesspeople or welfare recipients. Looked at another way, social conservatives were marginally more prejudiced against atheists than Evangelical Christians $(b=-.17, S E=.09,95 \%$ CIs $[-.35, .01], t=-1.89, p=$ $.061)$, and social liberals were more prejudiced against Evangelicals than atheists $(b=.32, S E=$ $.05,95 \%$ CIs $[.22, .42], t=6.11, p<.001)$. Social Ideology did not predict differences in prejudice against one target group that varied in economic dimension over another $(p s>.376)$.

Despite the fact that it did not reach statistical significance, we explored the Economic Ideology $\times$ Orientation $\times$ Dimension interaction, as its effects were at least in the expected direction. Figure 4C and 4D display the Economic Ideology $\times$ Orientation $\times$ Dimension interaction. Although in the expected directions, Economic Ideology did not significantly predict prejudice toward welfare recipients $(\mathrm{p}=.222)$, and was only marginally negatively associated with prejudice against businesspeople $(p=.092)$. Economic Ideology was unrelated to prejudice against Evangelical Christians or atheists. Looked at another way, economic conservatives were somewhat more prejudiced against welfare recipients than businesspeople, although the effect did not reach significance $(b=-.12, S E=.08,95 \%$ CIs $[-.27, .03], t=-1.62, p=.106)$, and economic liberals were more prejudiced against businesspeople than welfare recipients $(b=.24$, $S E=.11,95 \%$ CIs $[.02, .46], t=2.16, p=.032)$. Economic ideology did not significantly predict prejudice against one target group that varied in social dimension over another $(p s>.051)$. 
Testing the social primacy hypothesis. Comparisons of the Social Ideology $x$ Orientation $\times$ Dimension and Economic Ideology $\times$ Orientation $\times$ Dimension interactions suggests support for the social primacy hypothesis. To formally test this hypothesis, we compared the absolute values of the regression coefficients associated with the key three-way interactions through model constraint in Mplus 7. These results support the social primacy hypothesis. For worldview conflict, the Social Ideology $\times$ Orientation $\times$ Dimension interaction effect was significantly larger than the Economic Ideology $\times$ Orientation $\times$ Dimension interaction effect for both outcomes (worldview conflict: Wald $\chi^{2}=11.89, d f=1, p<.001$; prejudice: Wald $\left.\chi^{2}=8.56, d f=1, p=.003\right)$.

Testing mediation via worldview conflict. We performed path analysis using Mplus 7 to examine the indirect effects of the Social Ideology $\times$ Orientation $\times$ Dimension and Economic Ideology $\times$ Orientation $\times$ Dimension interactions on prejudice via worldview conflict. Prejudice was specified as the outcome variable, worldview conflict as the mediator, and all variables and interaction terms from the moderated multiple regression analyses as independent variables, allowed to predict both prejudice and worldview conflict. Worldview conflict predicted prejudice $(b=.31, S E=.03, p<.001)$. The Social Ideology $\times$ Orientation $\times$ Dimension interaction predicted worldview conflict $(b=1.51, S E=.41, p<.001)$, but the Economic Ideology $\times$ Orientation $\times$ Dimension interaction did not reach significance $(b=-.58, S E=.37, p=.116)$. The indirect effect for the Social Ideology $\times$ Orientation $\times$ Dimension interaction was significantly different from zero $(b=.47, S E=.13,95 \%$ CIs $[.20, .73], p=.001)$. Although in the expected direction, the indirect effect did not reach significance for the Economic Ideology $\times$ Orientation $\times$ Dimension interaction $(b=-.18, S E=.12,95 \%$ CIs $-.41, .05, p=.125)$.

\section{Discussion}


Study 2 offered mixed support for the dimension-specific symmetry hypothesis. Social but not economic ideology was predictive of prejudice against targets on the social dimension, and this effect was mediated by worldview conflict. While the symmetrical patterns anticipated by the dimension-specific hypothesis were evident on the economic dimension, the effects were clearly less strong on this dimension than on the social dimension, not all predicted effects were significant, and the mediation via worldview conflict did not reach significance. These findings do offer full support for the social primacy hypothesis. There was no support for the socialspecific asymmetry hypothesis, as worldview conflict and prejudice emerged equally among social liberals and conservatives.

\section{Study 3}

Some evidence suggests that people are reluctant to express negative attitudes toward some target groups, and that negative attitudes may be revealed through relatively automatic negative associations with those groups (Greenwald et al., 1998). If people are more reluctant to express negative attitudes toward groups that vary on the economic dimension than on the social dimension, this could explain the support for the social primacy hypothesis observed in Study 2. Alternatively, replicating Study 2's findings across both explicit and automatic measures and in a new sample would provide increased support for the social primacy hypothesis.

To test these ideas, we used the Implicit Association Test (IAT; Greenwald et al., 1998), which measures the relative strength of association between a target concept (e.g., "Black" or "White") and an attribute concept (e.g., "Good" or "Bad"). Whereas previous research has shown that conservatism predicts automatic negative associations with an array of left-wing, unconventional, or low status groups relative to right-wing, conventional, or high status groups (e.g., Jews vs. Christians, gays and lesbians vs. straight people, African-Americans vs. Whites; 
Cunningham, Nezlek, \& Banaji, 2004; Jost et al., 2008), to our knowledge, no studies have tested whether social and economic ideologies differentially predict dimension-specific negative group associations. We created two different IATs: one comparing socially conservative to socially liberal groups (i.e., Evangelical Christians vs. atheists, respectively), and another comparing economically conservative to economically liberal groups (investment bankers vs. welfare recipients, respectively). We included explicit measures of prejudice (i.e., feeling thermometer and social distance ratings) toward these groups.

\section{Method}

\section{Participants}

We recruited 124 U.S. residents (45\% Female, $74 \%$ White, $M_{\text {age }}=35$ years) through Mturk.

\section{Materials and Procedure}

Participants first completed the social groups and economic groups IATs, in random order. We used an open-source software package (Mason, 2011) that implements IATs using JavaScript and HTML. Participants completed the IATs in a web browser, and their responses were stored by the web server.

Both IATs consisted of five practice blocks and two critical blocks (as described in Nosek, Greenwald, \& Banaji, 2005). In the first (20-trial) practice block, participants used two response keys to sort words representing the target categories (investment bankers/welfare recipients or Evangelical Christians/Atheists, depending on test). In the second (20-trial) block they used the same two keys to sort positively and negatively valenced trait words as "warm" or "cold," and in the third (40-trial) practice block they used the two keys to sort stimuli representing the target categories and valenced words simultaneously (e.g., Rudman, Greenwald, 
\& McGhee, 2001). Immediately after the third practice block, participants encountered the first (40-trial) critical block, which was identical to the practice block they had just completed. Following the first critical block, key assignments were changed such that the keys used to indicate target categories were switched (e.g., the key previously indicating "Evangelical Christians" now indicated "Atheists" and vice versa). Participants were given one practice block in which they sorted stimuli representing the target categories in order to learn the new key assignments, and then a final practice block in which they simultaneously sorted valenced words and the target categories, in the opposite combination as before (e.g., if a participant had previously been told to categorize "Atheists" and "pleasant" together, he or she was now told to categorize "Atheists" and "unpleasant" together). The second 40-trial critical block followed this final practice block.

In both IATs, participants saw the same positively (honest, kind, warm, polite, thoughtful) and negatively (slimy, cold, cruel, rude, shallow) valenced words. The IAT assessing attitudes towards Evangelical Christians (believer, religious, devout, creationism, faith) vs. Atheists (nonbeliever, nonreligious, skeptical, evolution, doubt) was labeled "Religion IAT," and the IAT assessing attitudes towards bankers (rich, wealth, millionaire, Wall Street, corporation) vs. welfare recipients (poor, poverty, benefit check, public housing, unemployed) was labeled "Economy IAT."

After completing both IATs, participants completed a questionnaire in which they rated the four targets on feeling thermometer ratings $(0=$ very cold; $100=$ very warm $)$, a single social distance item ("How close of a relationship would you be willing to have with members of each of the following groups?": 1 = not even as a citizen of my country; $2=$ only as a citizen of my country; 3 = as a co-worker in my same occupation; $4=$ as a neighbor on my street; $5=$ as my 
close personal friend; 6 = as a spouse or romantic partner; derived from Bogardus, 1933), and the same worldview conflict item used in Study 2 (one item for each of the targets). The order of these items was randomized. Feeling thermometer and social distance rating were reverse-scored so that higher scores indicated more prejudice; because they were highly correlated for each target (all $r \mathrm{~s}>.58$ ), we combined them by first converting each to a $0-1$ scale and then averaging across the two measures. Participants then completed measures of social and economic ideology, party identification, and demographics identical to Study 2.

\section{Results}

\section{Preliminary Analyses}

We computed IAT $D$ scores using the scoring algorithm described in Greenwald et al. (1998). Higher $D$ scores corresponded to stronger implicit preferences for liberal over conservative targets. For comparison, we computed difference scores for the explicit prejudice variables so that higher scores reflect greater prejudice and worldview conflict toward conservative relative to liberal targets. Table S8 reports the correlations among and descriptive statistics for the study variables. ${ }^{5}$

\section{Primary Analyses}

We tested the dimension-specific symmetry hypothesis with path analysis using Mplus 7. The two IAT and two explicit difference score measures were entered as outcome variables, the social groups' and economic groups' worldview conflict difference scores as mediators, and participant social and economic ideology as independent variables, which were allowed to

${ }^{5}$ Contrary to Jost and Krochik (2014), the explicit-implicit relationships were not higher among conservatives, as neither social nor economic political ideology moderated these relationships (all $p \mathrm{~s}>.23$ ). 
predict the outcomes. Residual were allowed to correlate in this fully saturated model. ${ }^{6}$ With the exception of the economic IAT score, the dimension-specific worldview conflict variable predicted the corresponding outcome variable (i.e., worldview conflict with social groups predicted social explicit prejudice and IAT scores, $b \mathrm{~s}>.05, p \mathrm{~s}<.01$, and worldview conflict with economic groups predicted economic explicit prejudice, $b=.08, S E=.02, p<.001$, but not the economic IAT, $b=.01, S E=.02, p=.524)$, whereas the other worldview conflict measure did not (i.e., worldview conflict with economic targets did not predict explicit prejudice or IAT scores for social groups, $p \mathrm{~s}>.690$, and worldview conflict with social targets did not predict explicit prejudice or IAT scores for economic groups, $p s>.717)$. Further, social $(b=-1.05, S E=$ $.30, p<.001)$ but not economic $(b=-.31, S E=.18, p=.092)$ ideology significantly predicted the social groups worldview conflict difference score, whereas economic $(b=-.52, S E=.17, p=$ $.002)$ but not social $(b=-.07, S E=.31, p=.827)$ ideology predicted the economic groups' worldview conflict difference score.

To test the social-specific asymmetry hypothesis, we compared the average IAT scores among socially liberal and conservative participants to 0 , under the presumption that an IAT $D$ score of 0 reflects absence of bias (see Greenwald, Nosek, \& Banaji, 2003), with the caveat that an IAT D score of 0 may not reflect an absence of bias (see Blanton, Jaccard, Strauts, Mitchell, \& Tetlock, 2015). Participants both 1 SD above and below the social ideology midpoint had negative $D$ scores on average that were significantly different from 0 , indicating that they each had more positive associations with Evangelical Christians than atheists (social liberals: $b=-.50$, $S E=.06, t=8.57, p<.001$; social conservatives: $b=-.41, S E=.11, t=3.76, p<.001)$. Whereas

\footnotetext{
${ }^{6}$ Controlling for demographic characteristics (age, gender, ethnicity, education, SES), results were identical with the exception that both economic and social ideology significantly predicted worldview conflict difference scores for the economic target.
} 
social liberals' explicit prejudice against Evangelicals was significantly different from the 0 point, $b=.23, S E=.05, t=4.91, p<.001$, social conservatives' prejudice against atheists was only marginally significantly from the 0 point, $b=-.16, S E=.09, t=-1.74, p=.085$. Further, whereas social liberals' worldview conflict with Evangelicals was significantly different from the 0 point, $b=2.11, S E=.38, t=5.51, p<.001$, social conservatives' worldview conflict with atheists was only marginally significantly from the 0 point, $b=-1.35, S E=.72, t=-1.87, p=$ .064. The results on the explicit prejudice and worldview conflict measures each indicate no support for the social-specific symmetry hypothesis. The results on the D score suggest that both social conservatives and liberals hold more positive associations toward stimuli associated with Evangelical Christians than with atheists. This counterintuitive finding, especially when paired with the explicit prejudice and worldview conflict results, is consistent with suggestions that the IAT may capture broad societal or cultural views rather than personal attitudes (e.g., Olson, Crawford, \& Devlin, 2009).

To test the social primacy hypothesis, we used path constraint modeling in Mplus 7 to compare the regression coefficients for social ideology's relationship with social target outcome variables (i.e., worldview conflict, explicit prejudice, IAT score) to those for economic ideology's relationship with economic target outcome variables, while controlling for the opposing effects (e.g., comparing the effect of social ideology on social target explicit prejudice to the effect of economic ideology on economic target prejudice, while controlling for the effect of economic ideology on social target explicit prejudice, and for the effect of social ideology on economic target prejudice). This is a similar analytic approach to the multiple regression models reported throughout this paper. While there were no differences on IAT scores (Wald $\chi^{2}=.38, d f$ $=1, p=.536$ ), the effects of social ideology on worldview conflict with and explicit prejudice 
toward social targets were stronger than the effects of economic ideology on economic targets (worldview conflict: Wald $\chi^{2}=27.99, d f=1, p<.001$; explicit prejudice: Wald $\chi^{2}=19.27, d f=$ $1, p<.001)$. Thus, with the exception of IAT scores, these results again reveal support for the social primacy hypothesis.

Testing mediation via worldview conflict. The indirect effects of social and economic ideology via worldview conflict were tested within the same fully saturated model used to test the dimension-specific symmetry hypothesis. In all cases except the economic groups IAT score, the indirect effects via worldview conflict were significant (social groups explicit prejudice: $b=$ $.10, S E=.03,95 \%$ CIs [-.16, -.04], $p<.001$; economic groups explicit prejudice: $b=-.04, S E=$ $.02,95 \%$ CIs [-.07, -.01], $p=.009$; social groups IAT: $b=-.05, S E=.02,95 \%$ CIs [-.09, -.01], $p$ $=.013$; economic groups IAT: $b=-.01, S E=.01,95 \% \mathrm{CIs}[-.03, .02], p=.556)$. The fact that the mediation effects were significant for the social IAT but not the economics IAT lends some support to the social primacy hypothesis.

\section{Discussion}

In Study 3, the dimension-specific symmetry hypothesis received clear support on explicit measures of prejudice: social and economic ideology differentially predicted explicit prejudice against groups who varied in their own social and economic ideology, respectively, and these relationships were mediated by dimension-specific worldview conflict with the targets. At the same time, the social primacy hypothesis also received support on explicit prejudice, as the effects were stronger on the social than the economic dimension. There was no support for the social-specific asymmetry hypothesis in this study. Although the relative lack of political conservatives in the sample may have made it less likely that significant biases among them would emerge, the clear biases among political liberals is inconsistent with the social-specific 
asymmetry hypothesis. In total, findings on explicit measures from Study 3 replicate those from Study 2.

The results on the IAT were less consistent. Social ideology did not directly predict social IAT scores; however, it did have a significant indirect effect on IAT scores via worldview conflict. This may be because worldview conflict is a more proximal antecedent of prejudice than political orientation, and that individual differences variables (such as political orientation) tend to be more robustly related to explicit than automatic measures (Nosek, 2005). Whereas social IAT scores were related to worldview conflict with and explicit prejudice against social but not economic groups (as expected by the dimension-specific symmetry hypothesis), economic IAT scores were only weakly related to explicit prejudice against economic groups, and unrelated to worldview conflict with the economic groups (see Table S8). Thus, economic ideology did not have direct or indirect effects on economic IAT scores (see also Nosek, 2007, who found stronger implicit-explicit correspondence on socially-related IATs [e.g., religionatheism] than on economically-related IATs [i.e., rich people-poor people]). Again, these results are consistent with the social primacy hypothesis, suggesting that whereas political hostility exists along the economic dimension, it appears more intense along the social dimension.

\section{Study 4}

Whereas people may be willing to express animosity toward people with conflicting worldviews, they may be more reluctant to behaviorally discriminate against them. To examine this possibility, in Study 4 we employed the dictator game, a resource allocation game in which participants are assigned the role of "giver" and instructed to allocate a resource between themselves and a "receiver," often a target individual whom the participant never meets. The giver is instructed to divide the resource between himself or herself and the receiver in any way 
s/he chooses. The dictator game has been used with increasing frequency to examine intergroup biases (e.g., Bendersky, 2014; Rand, Pfeiffer, Dreber, Sheketoff, Wernerfelt, \& Benkler, 2009), and has been described as offering the opportunity to assess "pure" group dislike and prejudice (Fershtman \& Gneezy, 2001; Iyengar \& Westwood, 2014).

Recent studies used this paradigm to examine discrimination against people with morally or politically dissimilar beliefs. For example, Wright, Cullum, and Schwab (2008) found that people behaved more selfishly in the dictator game (i.e., allocated more of the resource to themselves than the target) when they believed they were interacting with another person who differed from them on a moral issue compared to when they interacted with another person with whom they differed on a non-moral issue. Other evidence indicates that partisans give more resources to fellow partisans than opposing partisans (e.g., Rand et al., 2009), and that these biases occur over and above the effects of target ethnicity (Iyengar \& Westwood, 2014). These studies have not looked at different dimensions of ideology.

Study 4 not only extends tests of multi-dimensional ideological conflict from attitudes to behavior, but from intergroup to interpersonal perceptions, as targets in Study 4 were ostensibly individual fellow undergraduate students of the participant. Further, unlike Studies 1-3 in which participants' ideology and target judgments were measured at the same time, participants' ideology was measured at least 24 hours in advance of target judgments, reducing the influence of consistency effects in people's responses.

\section{Method}

\section{Participants}

We sampled from The College of New Jersey Psychology Department participant pool until the end of the semester. Data from 188 students were collected. Fourteen students were 
removed for suspicions regarding the experimental manipulation, leaving 174 participants (82\% female; $70 \%$ White, $M_{\text {age }}=19$ years $)$ in the final analysis. Suspicion was not assessed in any of the other present studies.

\section{Materials and Procedure}

Online pre-experimental information intake. Participants first completed an online survey at least twenty-four hours before arriving at the lab. During the online portion, participants were told that they would be taking part in a study titled, "Stranger Impressions and Interactions," and that when they arrived at the lab, they would be asked to form impressions of and interact with another participant whom they knew they would never actually meet face-toface. They were told that all participants would be asked to write two brief essays during the online portion: one about their religious beliefs and another about their career goals. (This was done in order to bolster the rationale behind the experimental manipulation, described below.) Participants were told that when they arrived at the lab, they would read an essay written by another participant, and that this other participant would read one of the participant's essays. After reading these instructions, participants wrote the two brief essays, in random order. We then assessed social and economic ideology (higher scores reflected greater conservatism), party identification, and demographic information.

Target information and impression ratings. After verifying that participants had completed the online portion prior to arrival to the lab, participants were directed to the computer. They were instructed that they would read the essay of another participant, and based on that essay, would be asked several questions about that participant. Participants were randomly assigned to one of four essays ostensibly written by a fellow student: an Evangelical Christian (socially conservative, $N=36$ ), an atheist (socially liberal; $N=50$ ), a student who 
planned to work as an investment banker upon graduation (economically conservative, $N=41$ ), or a student who planned to be a social services worker upon graduation (economically liberal, $N$ =47). Embedded in each of these essays, the ostensible target wrote about his or her political beliefs. Thus, although participants could have gleaned ideological dimension and direction from the ostensible target group (e.g., atheist), dimension and direction were also fairly explicitly identified (see Appendix I in SOM for essay text). Thus, as in Study 2, targets were varied in a 2 (Orientation: liberal, conservative) $\times 2$ (Dimension: social, economic) between-subjects design

After reading the essay, participants evaluated the target on several indicators. In addition to the feeling thermometer and social distance items (higher scores indicated more prejudice; as in Studies 2 and 3, these items were strongly correlated with one another, $r=.51, p<.001$, rescaled to $0-1$ scales and averaged to create a prejudice measure) and the worldview conflict item used in the previous studies, participants were also asked to guess the target's gender, age, ethnicity, religiosity, and SES in order to mask the items of interest and bolster the cover story about stranger impression formation.

Dictator game. Participants were next told that they would have a distant interaction with the other participant. They were given the instructions for the dictator game, and were told that they were randomly assigned to the giver role (actually, all participants were assigned this role). Participants were provided ten raffle tickets and told that they could choose how many raffle tickets to keep for themselves and how many to give to the other participant (Wright et al., 2008). They were told that each raffle ticket would be entered into a drawing for one of four $\$ 25$ Visa gift cards, and were instructed to write their participant number on the back of the raffle tickets they planned to keep for themselves, and the participant number of the other participant (provided by the experimenter) on the back of the raffle tickets they planned to give to the other 
participant (i.e., the receiver). Participants were instructed to place the ten tickets into a container, which had a slot at the top in order to insert the tickets. Extra tickets had been taped to the bottom of the container to bolster the illusion that the raffle tickets would not be counted directly afterwards and would be left in the container.

Once the participants affirmed that they understood the instructions, the experimenter left the room to allow the participant to perform the task in private. Upon completion, the experimenter returned to the room to probe for suspicion before being debriefed and excused.

\section{Results}

\section{Preliminary Analyses}

Ticket allocation to oneself is the measure of discrimination, with higher scores indicating greater discrimination against the other participant. The distribution of scores ranged from 0 to 10, and appeared normally distributed (skewness rating: -.29). The distributions within three of the four conditions appeared relatively normal (skewness ratings less than the absolute value of .77); however, the distribution within the Atheist condition appeared positively skewed (skewness $=2.03$ ). Therefore, following Bendersky's (2014) treatment of skewed data resulting from a dictator game study, we squared the ticket allocation variable. ${ }^{7}$ The average amount of ticket allocation to oneself in Study $4(M=5.47)$ is similar to levels observed in Bendersky (2014; $M=5.82$ ) and close to an equal division of the tickets. Table S9 reports the descriptive statistics for and correlations among the study variables. Critically, ticket allocation to oneself was significantly related to prejudice and worldview conflict, suggesting that it is related to other common measures of prejudice.

\section{Primary Analyses}

\footnotetext{
${ }^{7}$ The conclusions are unchanged when using the untransformed ticket allocation variable.
} 
We performed three separate moderated multiple regression analyses for worldview conflict, prejudice, and ticket allocation. In each model, Social Ideology (midpoint-centered), Economic Ideology (midpoint-centered), Orientation ( 0 = left-wing, 1 = right-wing), and Dimension $(0=$ social, $1=$ economic $)$ were entered in Step 1, all two-way interactions in Step 2, and all three-way interactions in Step 3. ${ }^{8}$ Table 3 reports Step 3 of the models for worldview conflict, prejudice, and ticket allocation. The full models are reported in Tables S10 - S12 in SOM.

Worldview conflict. The Social Ideology $\times$ Orientation $\times$ Dimension interaction was significant. Whereas the Economic Ideology $\times$ Orientation $\times$ Dimension interaction was in the opposite direction as expected by the dimension-specific symmetry hypothesis, it did not reach significance $(p=.172)$.

Figure 5A \& 5B display the Social Ideology $\times$ Orientation $\times$ Dimension interaction. Social Ideology positively predicted worldview conflict regarding the atheist student and negatively predicted worldview conflict regarding the Evangelical Christian student, whereas Economic Ideology did not predict worldview conflict regarding these social targets. Further, whereas social conservatives saw greater worldview conflict with the atheist than with the Evangelical $(b=-3.38, S E=.82,95 \%$ CI $[-5.00,-1.77], t=-4.14, p<.001)$, social liberals saw greater worldview conflict with the Evangelical than with the atheist $(b=1.30, S E=.42,95 \% \mathrm{CI}$ $[.48,2.12], \mathrm{t}=3.14, p=.002)$. Social Ideology did not predict differences in perceived worldview conflict regarding one economic target over another ( $p s>.246)$.

\footnotetext{
${ }^{8}$ After controlling for interactions with demographic covariates (age, gender, ethnicity, SES), the Economic Ideology $\times$ Orientation $\times$ Dimension interaction on prejudice was significant when controlling for SES, and non-significant when controlling for ethnicity $(p=.19)$. The marginally significant interaction effects on ticket allocation were either marginally significant or non-significant $(p s<.14)$ with covariates included. All other tests were unaffected by controlling for demographic characteristics.
} 
Figure 5C and 5D display the Economic Ideology $\times$ Orientation $\times$ Dimension interaction. Neither Economic nor Social Ideology significantly predicted worldview conflict regarding the economic targets $(p s>.141)$. Further, Economic Ideology did not predict differences in perceived worldview conflict regarding one economic target over another ( $p$ s $>.364)$, although economic liberals experienced greater worldview conflict with the Evangelical than with the atheist ( $p=.030$; there was no effect among economic conservatives, $p=.542$ ).

Prejudice. The Social Ideology $\times$ Orientation $\times$ Dimension interaction and Economic Ideology $\times$ Orientation $\times$ Dimension interactions were both significant, of roughly equal size, and in opposite directions.

Figure $6 \mathrm{~A}$ and $6 \mathrm{~B}$ display the Social Ideology $\times$ Orientation $\times$ Dimension interaction. Social Ideology positively predicted prejudice against the atheist student and negatively predicted prejudice against the Evangelical Christian student, and Economic Ideology did not significantly predict prejudice against these social targets (although Economic Ideology had marginal positive effects on prejudice against Evangelical Christians, $p=.059$ ). Further, whereas social conservatives were more prejudiced against the atheist than the Evangelical $(b=-.29, S E=$ $.08,95 \%$ CI $[-.45,-.13], \mathrm{t}=-3.63, p<.001)$, social liberals were more prejudiced against the Evangelical than the atheist $(b=.12, S E=.04,95 \% \mathrm{CI}[.04, .20], \mathrm{t}=2.86, p=.005)$. Social Ideology did not predict biases against one economic target over another $(p s>.202)$.

Figure 6 Panels C and D show the Economic Ideology $\times$ Orientation $\times$ Dimension interaction. None of the slopes were statistically significant $(p s>.489)$. Further, Economic Ideology did not predict biased prejudice responses regarding one economic target over another ( $p$ s $>$.248). Economic conservatives were not more biased against one target over another $(p=$ 
.767); however, unexpectedly, economic liberals expressed more prejudice against the Evangelical Christian than the atheist $(p=.030)$.

Discrimination (ticket allocation). Both the Social Ideology $\times$ Orientation $\times$ Dimension and the Economic Ideology $\times$ Orientation $\times$ Dimension interactions were marginally significant ( $p$ s $=.073$ and .054 , respectively), and in opposite directions.

Figure 7A and 7B display the Social Ideology $\times$ Orientation $\times$ Dimension interaction. Social Ideology did not predict discrimination against the atheist but did against the Evangelical Christian, indicating that social liberalism was associated with greater discrimination against the Evangelical Christian. Economic Ideology was unrelated to discrimination against the Evangelical Christian, but did predict discrimination against the atheist, suggesting that economic conservatism was associated with greater discrimination against the atheist. Further, social conservatives appeared more discriminatory when interacting with the atheist than with the Evangelical Christian $(b=-11.47, S E=9.33,95 \%$ CI $[-29.91,6.97], t=-1.23, p=.221)$, whereas social liberals appeared more discriminatory when interacting with the Evangelical Christian than with the atheist $(b=4.79, S E=4.68,95 \%$ CI $[-4.45,14.03], t=1.03, p=.307)$, although neither of these effects were statistically significant. Social Ideology did not predict biases in favor of economic target over another $(p s>.349)$.

Figure 7C and 7D display the Economic Ideology $\times$ Orientation $\times$ Dimension interaction. Economic Ideology marginally predicted discrimination against the social services worker $(p=$ $.065)$ indicating that economic conservatism predicted greater discrimination against this target, but it was unrelated to discrimination against the investment banker $(p=.270)$. Social ideology did not predict discrimination against these economic targets. Further, economic conservatives were marginally more discriminatory when interacting with the social services worker than with 
the investment banker $(b=-10.24, S E=5.69,95 \%$ CI $[-21.48, .1 .01], t=-1.80, p=.074)$, whereas economic liberals were marginally more discriminatory when interacting with the investment banker than with the social services worker $(b=17.50, S E=8.88,95 \%$ CI [-.031, 35.04], $t=1.97, p=.050)$. Economic Ideology did not predict biases in favor of one social target over another $(p s>.587)$.

Testing the social primacy hypothesis. To formally test the social primacy hypothesis, we compared the absolute values of the regression coefficients associated with the key three-way interactions through model constraint in Mplus 7. Inconsistent with the social primacy hypothesis, none of the effects were statistically significant (worldview conflict: Wald $\chi^{2}=1.90$, $d f=1, p=.168$; ticket allocation: Wald $\chi^{2}=.46, d f=1, p=.496$; prejudice: Wald $\chi^{2}=1.10, d f=$ $1, p=.295)$, although the effect on worldview conflict was in the expected direction.

Testing mediation via worldview conflict. Using Mplus 7, we performed a path analysis to examine the indirect effects of the Social Ideology $\times$ Orientation $\times$ Dimension and Economic Ideology $\times$ Orientation $\times$ Dimension interactions on prejudice and ticket allocation via worldview conflict. Prejudice and ticket allocation were specified as separate outcome variables, worldview conflict as the mediator, and all variables and interaction terms from the moderated multiple regression analyses as independent variables. Worldview conflict significantly predicted prejudice $(b=.14, S E=.05, p=.002)$ but not ticket allocation $(b=.09, S E=.11, p=.434)$. There was an indirect effect of the Social Ideology $\times$ Orientation $\times$ Dimension on prejudice via worldview conflict $(b=.17, S E=.08, p=.042,95 \%$ CIs $[.01, .33])$. However, because the Economic Ideology $\times$ Orientation $\times$ Dimension interaction effect did not significantly predict worldview conflict $(b=-.69, S E=.54, p=.202)$, its indirect effects were not significant $(p \mathrm{~s}>$ .249). Further, because worldview conflict did not significantly predict ticket allocation in the 
model (despite the significant bivariate relationship between the two; see Table S9), there were no significant indirect effects of either interaction effect on ticket allocation ( $p$ s $>.477)$.

\section{Discussion}

Study 4 largely replicated Studies 1-3. Specifically, social (but not economic) ideology predicted worldview conflict with and prejudice against social (but not economic) targets. These effects were moderated by the target's ideological orientation, and mediated by worldview conflict. However, whereas economic liberals were somewhat more prejudiced against the future investment banker than they were against the future social services worker, no other effects of economic ideology on worldview conflict or prejudice against the economic targets emerged.

Study 4 provided mixed support for extending the dimension-specific symmetry hypothesis from attitudes to behavior. Social (but not economic) ideology predicted discrimination against the Evangelical Christian, but not against the atheist. The pattern of results suggested that social liberals and conservatives tended to discriminate against Evangelical and atheist targets, respectively, although these effects were not significant. Economic (but not social) ideology marginally or significantly predicted discrimination against the economic targets in the expected direction, and economic conservatives were marginally more discriminatory against the social services worker whereas economic liberals were marginally more discriminatory against the investment banker. However, because worldview conflict did not predict discrimination in the fully saturated mediational model (despite its significant bivariate relationship with discrimination), these effects of social and economic ideology on discrimination were not mediated by worldview conflict. Although none of the formal tests of the social primacy hypothesis were significant, the results regarding worldview conflict were certainly in line with it, offering at least mixed support. Finally, the social-specific asymmetry 
hypothesis received no support, as biases among social liberals emerged on all three outcome measures.

Two important caveats may explain the weakness of the above findings relative to Studies 1-3, especially in regards to worldview conflict. First, unlike Studies 1 - 3, participant ideologies in Study 4 were assessed at least 24 hours prior to target evaluations. If participants' ideologies were a less salient consideration during target evaluation, this may have rendered worldview conflict less potent. Second, although we manipulated worldview conflict via the ostensible target's essays, all participants knew that the target was a member of their ingroupfellow psychology students at the same college. This may have especially dampened perceptions of worldview conflict with the economic targets, who because they were describing their career goals may have appeared more relatable to college-age participants. Indeed, this appears reflected in the main effect for target dimension on worldview conflict (see Table S10).

\section{Study 5}

Studies 2-4 varied target orientation (left vs. right) and dimension (social vs. economic) using social group labels. Providing social group labels allows us to explicitly link participants' political beliefs to their prejudices against actual social groups, rather than capturing simple partisan dislike. However, this strategy also means that characteristics associated with these social groups other than their politics (e.g., status, wealth, ethnicity, gender) may also shape people's responses to them. Therefore, in Study 5, we varied target orientation and dimension without providing information about social group membership. Moreover, we kept some demographic information (e.g., age, gender, occupation) constant across targets to control for their possible influence. This strategy should serve to isolate the effect that dimension-specific ideological dissimilarity has on prejudice. 
We also expanded the measures of prejudice in Study 5. Although feeling thermometer and social distance ratings are the most common measures of prejudice in the literature (Correll, Judd, Park, \& Wittenbrink, 2010), they may not capture important differences in dimensionbased prejudice revealed by other intergroup attitude measures. To generalize our findings, we included a number of other prejudice measures meant to tap into multiple aspects of prejudice, including behavioral intentions (political intolerance; Skitka, Liu, Yang, Chen, Liu, \& Xu, 2013), stereotypes and beliefs (trait ratings; e.g., Flynn, 2005), and intergroup emotions (Cottrell \& Neuberg, 2005).

Finally, we shifted our measurement of ideology in Study 5 from self-identification to issue-based measures. We chose the identification approach for Studies 1-4 because policy positions used to measure ideology (e.g., marriage equality) often have considerable content overlap with targets of prejudice (e.g., gay men and lesbians). However, given that we now consider targets for whom we do not provide any social group information, it is now possible to measure ideology with issues positions. Therefore, in Study 5, we generalize our findings to this alternative measurement of social and economic ideologies.

\section{Method}

\section{Participants}

Study 5 had a similar design to Study 2, and was also collected on MTurk. As a replication of Study 2, we collected a sample 2.5 times larger than Study 2's (Simonsohn, 2015). We therefore recruited 625 participants. After excluding 40 participants who failed an attention check, 585 remained in the final analysis ( $57 \%$ female; $75 \%$ White; $M_{\text {age }}=35$ years). Study 5 was the only one of the present studies to include such an attention check.

\section{Materials and Procedures}


Participants were randomly assigned to one of four targets. Each target labeled himself as either a "pretty strong" social liberal $(N=143)$, social conservative $(N=142)$, economic liberal $(N=150)$, or economic conservative $(N=150)$. Both liberal targets indicated that they preferred MSNBC, whereas both conservative targets indicated they preferred Fox News. Both targets on the social dimension indicated that they blogged about issues like same-sex marriage and abortion, whereas both targets on the economic dimension indicated that they blogged about issues like taxation and wealth distribution. All four targets provided information about their gender (male), ethnicity (White), citizenship (United States), occupation (communications analyst), personality, and life goals (see Appendix II in SOM for target vignettes).

Participants then evaluated the target on twelve positive and seven negative traits $(1=$ not at all; $10=$ extremely), which were drawn from research on the relationship between Openness to Experience and prejudice (Flynn, 2005) and subtle dehumanization (e.g., impatient, shallow; Loughnan \& Haslam, 2007). Trait order was randomized.

Participants then completed a 4-item social distance measure, which asked participants how willing they would be to work with the target, meet the target, have the target marry into their family, and have the target as a close personal friend $(1=$ very unwilling; $7=$ very willing; items reverse-scored so that higher scores indicate greater desired social distance). These items were averaged to form the social distance measure $(\alpha=.94)$. Participants then provided feeling thermometer ratings of the target $(0=$ very cold $; 100=$ very warm; reverse-scored so that higher values indicate more prejudice), and their overall impression of the target (Flynn, 2005; $1=$ very unfavorable, 7 = very favorable, reverse-scored so that higher values indicate more prejudice).

Participants then completed a 3-item political intolerance measure of "people like John" (e.g., "I think that people like John should not be allowed to organize in order to influence public 
policy;" $\alpha=.61 ; 1=$ strongly disagree; $6=$ strongly agree $)$, and feeling thermometer item towards "people like John" (also reverse-scored so that higher scores indicate more prejudice). Finally, participants completed Cottrell and Neuberg's (2005) 27-item measure of intergroup emotions toward "people like John" (1 = not at all; $7=$ extremely), which has subscales for thirteen intergroup emotions. Participants then indicated worldview conflict items similar to the ones used in the previous studies, with one for the individual target and another for "people like" the target $(1=$ not at all different from me; 7 = very different from me $)$.

Social and economic operational ideologies were then measured with six social attitude items ("Should same-sex couples be allowed to marry, or do you think they should not be allowed to marry?") and four economic attitudes items (e.g., "Do you believe that government should make incomes more equal or that we need larger income differences as incentives for individual effort?"; Malka et al., 2014). Social and economic items were presented on separate pages, with presentation order randomized. Items within each scale were also randomized. Because scales varied by item (i.e., 4-point, 5-point, and 7-point scales), we converted each item to range from 0 to 1 , with higher scores indicating more conservatism, and created separate social operational $(\alpha=.78)$ and economic operational $(\alpha=.80)$ scales. These are the primary predictors in Study $5 .^{9}$

\footnotetext{
${ }^{9}$ To verify that operational and self-placed ideologies were related to each other as anticipated, we regressed selfplaced social ideology on operational social and economic ideology, showing that operational social ideology $(b=$ 4.62, $S E=.26,95 \%$ CIs $[4.12,5.12], t=17.99, p<.001)$ was a better predictor of self-placed social ideology than was operational economic ideology $(b=1.88, S E=.25, t=7.40,95 \%$ CIs $[1.38,2.37], p<.001)$, as the upper bound $\mathrm{CI}$ of economic ideology was less than the lower bound CI of social ideology. On the other hand, in a separate regression equation, operational economic ideology $(b=3.90, S E=.27,95 \%$ CIs [3.37, 4.43], $t=14.58, p<.001)$ was a better predictor of self-placed economic ideology than was operational social ideology $(b=2.02, S E=.27$, CIs [1.49, 2.55], $t=7.47, p<.00195 \%$ ), as the upper bound CI of social ideology was less than the lower bound CI of economic ideology.
} 
Participants then provided demographic information (age, gender, ethnicity, education, income, SES) along with the same single-item 7-point self-placement measures of ideology, party, and social and economic ideology used in the previous studies. Finally, participants completed an attention check item (correctly recalling the target's college major), as well as two items assessing the target's perceived social and economic ideology.

\section{Results}

\section{Identifying Categories of Prejudice Variables}

To potentially simplify our analyses given the vast array of outcome measures in Study 5 , we used exploratory factor analyses to determine independent categories of variables.

Trait ratings. A principle components analysis with Oblimin rotation on the nineteen traits revealed a three-factor solution. Positive traits suggesting competence (ambitious, successful, intelligent, bright, thorough, responsible, sociable, curious) loaded on the first factor (eigenvalue $=7.99 ; 42.06 \%$ of the variance). All seven negative traits (hostile, aggressive, impatient, distractible, cold, shallow, impersonal) loaded on the second factor (eigenvalue $=$ $2.52 ; 13.25 \%$ of the variance). Positive traits suggesting warmth (humble, trusting, polite, likeable) loaded on the third factor (Eigenvalue 1.14; $6.00 \%$ of the variance). We therefore created competence trait $(\alpha=.90)$, negative trait $(\alpha=.86)$, and warmth trait $(\alpha=.83)$ scales, respectively, from these items.

Emotions. A principle components analysis with Oblimin rotation on the 27 emotion items revealed a four-factor solution. Several negative group-based emotions (anger, sadness, moral disgust, resentment, physical disgust, and general negative emotion) formed the first factor (eigenvalue $=13.87,51.37 \%$ of the variance $)$. Anxiety, fear, envy, and guilt formed the second factor (eigenvalue $=2.77 ; 10.24 \%$ of the variance), sympathy and pity formed the third factor 
(eigenvalue $=1.34 ; 4.96 \%$ of the variance $)$, and the two general positive emotion items formed the fourth factor (eigenvalue $=1.03 ; 3.82 \%$ of the variance). We formed four emotion scales (generally negative, $\alpha=.85$; anxiety-fear-envy-guilt, $\alpha=.86$; sympathy-pity, $\alpha=.56$; general positive, $r=.74$ ) based on these factor loadings.

Determining categories of prejudice variables. We performed a principle components analysis with Oblimin rotation with feeling thermometer ratings of the target individual, feeling thermometer ratings of the group, the four social distance items, unfavorable ratings of the target individual, the three political intolerance items, the 19 trait ratings, and the 27 emotion items. Eight factors were determined, although only four with eigenvalues greater than 1.70 , with the lowest four factors together accounting for only $9.47 \%$ of the variance. The first factor is formed by the negative intergroup emotions (eigenvalue $=22.47 ; 40.12 \%$ of the variance). The second factor consists of the social distance items, the two feeling thermometer ratings, and the unfavorable rating (eigenvalue $=5.63 ; 10.06 \%$ of the variance). The seventh factor consisted of the political intolerance items (eigenvalue $=1.20 ; 2.14 \%$ of the variance) whereas the remaining five factors reflected the differences between the emotion factors and trait factors discussed above.

Given this evidence, we tested our hypotheses on the following ten variables: warmth traits, competence traits, negative traits, negative intergroup emotions, anxiety/fear emotions, sympathy/pity emotions, envy/guilt emotions, positive emotions, general negative assessments (a composite measure of the two feeling thermometer ratings, social distance, and the unfavorability rating; all items were re-coded to $0-1$ and averaged to form the general negative assessment measure), and political intolerance. Because negative emotion was the only outcome variable characterized by high levels of skewness (skewness $>1$ ), we log transformed that 
variable. Table S13 reports the correlations among and $M$ s and SDs for social ideology, economic ideology, and the outcome variables.

\section{Primary Analyses}

In each moderated multiple regression model, Social Ideology (midpoint-centered), Economic Ideology (midpoint-centered), Orientation ( 0 = left-wing, 1 = right-wing), and Dimension $(0=$ social, $1=$ economic $)$ were entered in Step 1, all two-way interactions in Step 2, and all three-way interactions in Step 3. ${ }^{10}$ All full models are reported in Tables S14-S23.

Worldview conflict. Because worldview conflict with the individual and with the group were highly correlated $(r=.93)$, we collapsed across these two items to create a worldview conflict variable. Table 4 displays Step 3 the moderated multiple regression analysis on worldview conflict with the target. The Social Ideology $\times$ Orientation $\times$ Dimension interaction was significant $(p<.001)$. The Economic Ideology $\times$ Orientation $\times$ Dimension interaction was in the expected direction, but did not reach significance $(p=.121)$.

Figure $8 \mathrm{~A}$ and $8 \mathrm{~B}$ the Social Ideology $\times$ Orientation $\times$ Dimension interaction. Social Ideology positively predicted worldview conflict with socially liberal targets and negatively toward socially conservative targets. It was unrelated to worldview conflict with economically conservative targets, but positively related to worldview conflict with economically liberal targets. Social liberals (-1 SD) experienced greater worldview conflict with social conservatives than with social liberals, $b=1.76, S E=.21,95 \%$ CIs $[1.35,2.17], t=8.42, p<.001$, whereas social conservatives (+1 SD) experienced greater worldview conflict with social liberals than with social conservatives, $b=-2.19, S E=.35,95 \%$ CIs $[-2.88,-1.51], t=-6.30, p<.001$. Social

\footnotetext{
${ }^{10}$ After accounting for interaction effects with demographic covariates, (age, gender, ethnicity, education, income, SES), all key interaction effects remained significant or marginally significant, with the exceptions of the Social Ideology $\times$ Orientation $\times$ Dimension effect on competence and negative emotions while controlling for age, and on negative emotions when controlling for SES.
} 
liberals experienced greater worldview conflict with economic conservatives than with economic liberals, $b=1.01, S E=.20,95 \%$ CIs $[.61,1.40], t=5.02, p<.001$, whereas social conservatives experienced greater worldview conflict with economic liberals than with economic conservatives, $b=-.85, S E=.39,95 \%$ CIs [-1.61, -.09], $t=-2.19, p=.029$. In each case, however, the effects were stronger for the social relative to the economic targets.

Figure $8 \mathrm{C}$ and $8 \mathrm{D}$ display the Economic Ideology $\times$ Orientation $\times$ Dimension interaction. Economic Ideology positively predicted worldview conflict with economically and socially liberal targets to roughly equal degrees, and negatively with economically and socially conservative targets, although the effect was twice as large for economically conservative targets. Economic liberals (-1 SD) experienced greater worldview conflict with economic conservatives than with economic liberals, $b=1.47, S E=.38,95 \%$ CIs $[.73,2.21], t=3.92, p<$ .001 , whereas economic conservatives (+1 SD) experienced greater worldview conflict with economic liberals than with economic conservatives, $b=-1.31, S E=.23,95 \%$ CIs [-1.77, -.85$], t$ $=-5.63, p<.001$. Economic liberals $(-1 \mathrm{SD})$ experienced greater worldview conflict with social conservatives than with social liberals, $b=.71, S E=.34,95 \%$ CIs $[.05,1.37], t=2.11, p=.036$, whereas economic conservatives (+1 SD) experienced greater worldview conflict with social liberals than with social conservatives, $b=-1.14, S E=.25,95 \%$ CIs $[-1.64,-.65], t=-4.55, p<$ .001. Among economic liberals, the size of the bias against economic conservatives was about twice that than against social conservatives; however, economic conservatives' bias against economical liberals was equivalent to their bias against social liberals.

General negative assessment. Table 4 displays Step 3 the moderated multiple regression analysis on general negative assessment. The Social Ideology $\times$ Orientation $\times$ Dimension 
interaction was significant $(p=.002)$. The Economic Ideology $\times$ Orientation $\times$ Dimension interaction was in the expected direction, but did not reach significance $(p=.101)$.

Figure 9A and 9B display the Social Ideology $\times$ Orientation $\times$ Dimension interaction. Social Ideology positively predicted negative assessment of socially and economically liberal targets (but the effect was about twice as large for socially liberal targets), and negatively predicted negative assessment of socially conservative but not economically conservative targets. Social liberals had a more negative assessment of social conservatives than of social liberals, $b=$ $.25, S E=.03,95 \%$ CIs $[.19, .31], t=8.24, p<.001$, whereas social conservatives had a more negative assessment of social liberals than of social conservatives, $b=-.15, S E=.05,95 \%$ CIs [$.25,-.05], t=-3.05, p=.002$. Biases toward economic targets among social liberals $(p=.098)$ and social conservatives $(p=.096)$ were not significant.

Figure 9C and 9D display the Economic Ideology $\times$ Orientation $\times$ Dimension interaction. Economic Ideology was unrelated to negative assessment of either economically or socially liberal targets, and was negatively related to negative assessment of socially conservative but not economically conservative targets. Economic liberals had a slightly more negative assessment of economic conservatives than of economic liberals, although the effect did not reach significance, $b=.09, S E=.05,95 \%$ CIs $[-.02, .19], t=1.64, p=.102$. Economic conservatives had a more negative assessment of economic liberals than of economic conservatives, $b=-.13, S E=.03$, $95 \%$ CIs $[-.20,-.07], t=-4.00, p<.001$. Biases toward social targets among economic liberals $(p$ $=.075)$ and economic conservatives $(p=.859)$ were not significant.

Warmth traits. Table 5 displays Step 3 the moderated multiple regression analysis on warmth traits. Consistent with the dimension-specific symmetry hypothesis, the Social Ideology $\times$ Orientation $\times$ Dimension interaction was significant $(p=.049)$, whereas the Economic 
Ideology $\times$ Orientation $\times$ Dimension interaction was marginally significant in the opposite direction $(p=.093)$.

Figure $10 \mathrm{~A}$ and $10 \mathrm{~B}$ display the Social Ideology $\times$ Orientation $\times$ Dimension interaction. Social Ideology positively predicted warmth traits for socially conservative but not economically conservative targets, but was unrelated to warmth traits for either socially or economically liberal targets. Social liberals attributed more warmth traits to social liberals than to social conservatives, $b=-1.34, S E=.25,95 \%$ CIs $[-1.83,-.84], t=-5.29, p<.001$, whereas social conservatives showed no significant bias in warmth trait attribution for socially liberal and conservative targets, $b=.36, S E=.42,95 \%$ CIs [-.47, 1.19], $t=.85, p=.398$. Social liberals and social conservative did not express biases in warmth trait attribution, $p \mathrm{~s}>.265$.

Figure 10C and 10D display the Economic Ideology $\times$ Orientation $\times$ Dimension interaction. Economic Ideology was unrelated to warmth traits for either socially or economically conservative targets, and negatively predicted warmth traits for economically liberal targets but not for socially liberal targets. Economic liberals attributed more warmth traits to economic liberals than to economic conservatives, $b=-1.04, S E=.46,95 \%$ CIs [-1.93, -.14], $t$ $=-2.28, p=.023$, whereas economic conservatives attributed more warmth traits to economic conservatives than to economic liberals, $b=.77, S E=.28,95 \%$ CIs $[.22,1.33], t=2.74, p=$ .006. Biases toward social targets among economic liberals $(p=.055)$ and economic conservatives $(p=.528)$ were not significant.

Competence traits. Table 5 displays Step 3 the moderated multiple regression analysis on competence traits. The Social Ideology $\times$ Orientation $\times$ Dimension interaction was marginally significant $(p=.073)$. The Economic Ideology $\times$ Orientation $\times$ Dimension interaction was in the expected direction, but did not reach significance $(p=.276)$. 
Figure 11A and 11B display the Social Ideology $\times$ Orientation $\times$ Dimension interaction. Social Ideology predicted competence (but the effect was twice as large for socially conservative targets), but was unrelated to competence traits for both socially and economically conservative targets. Social liberals attributed more competence traits to social liberals than to social conservatives, $b=-1.37, S E=.22,95 \%$ CIs $[-1.80,-.93], t=-6.15, p<.001$, whereas social conservatives showed no significant bias in competence trait attribution, $b=.01, S E=.37,95 \%$ CIs $[-.72, .73], t=.02, p=.985$. Social liberals and social conservative did not express biases in competence trait attributions, $p \mathrm{~s}>.248$.

Figure $11 \mathrm{C}$ and $11 \mathrm{D}$ display the Economic Ideology $\times$ Orientation $\times$ Dimension interaction. Economic Ideology was unrelated to competence traits for either socially or economically conservative targets, and negatively predicted competence traits for economically liberal but not socially liberal targets. Economic liberals attributed more competence traits to economic liberals than to economic conservatives, $b=-.91, S E=.40,95 \%$ CIs $[-1.69,-.13], t=-$ $2.28, p=.023$, whereas economic conservatives attributed more competence traits to economic conservatives than to economic liberals, $b=.65, S E=.25,95 \%$ CIs $[.16,1.13], t=2.60, p=$ .010. Economic liberals attributed more competence traits to social liberals than to social conservatives, $b=-1.11, S E=.36,95 \%$ CIs $[-1.81,-.41], t=-3.10, p=.002$, whereas economic conservatives did not show a bias in competence trait attribution, $p=.344$.

Negative emotions factor. Table 5 displays Step 3 the moderated multiple regression analysis on negative emotions. The Social Ideology $\times$ Orientation $\times$ Dimension interaction was significant $(\mathrm{p}=.006)$. The Economic Ideology $\times$ Orientation $\times$ Dimension interaction was in the expected direction, but was not significant $(p=.504)$. We therefore do not interpret this interaction, although it is displayed in Figure 12C and 12D. 
Figure $12 \mathrm{~A}$ and $12 \mathrm{~B}$ display the Social Ideology $\times$ Orientation $\times$ Dimension interaction. Social Ideology predicted negative emotions toward socially but not economically liberal targets, and negatively predicted negative emotions toward socially but not economically conservative targets. Social liberals expressed more negative emotions toward social conservatives than social liberals, $b=.20, S E=.03,95 \%$ CIs $[.14, .26], t=6.42, p<.001$, whereas social conservatives expressed more negative emotions toward social liberals than social conservatives, $b=-.16, S E=$ $.05,95 \%$ CIs $[-.27,-.06], t=-3.07, p=.002$. Biases toward economic targets among social liberals $(p=.066)$ and social conservatives $(p=.210)$ were not significant.

General negative assessment, negative emotions, and warmth and competence traits were the only prejudice outcome measures to produce significant three-way interaction effects. To examine whether the relationships among these effects varied by condition, we regressed general negative assessment on negative emotion, warmth traits, and competence traits, within the four target conditions. Negative emotions strongly predicted negative assessment across conditions $(b s>.49, \beta s>.42, p s<.001)$, and warmth traits did as well $(b s>-.03, \beta s>-.22, p s<.05)$, although not as strongly. Competence traits predicted negative assessment of conservative targets $(b \mathrm{~s}>-.03, \beta \mathrm{s}>-.22, p \mathrm{~s}<.01)$, but were unrelated to negative assessments of social liberals $(p=$ $.400)$ and marginally related to assessment of economic liberals ( $b \mathrm{~s}>-.02, \beta \mathrm{s}>-.14, p \mathrm{~s}=.070)$. This suggests that competence judgments may be more strongly linked with prejudice for conservatives than for liberal targets.

Findings on other outcomes. The moderated multiple regression analyses on political intolerance, negative traits, anxiety-fear/envy-guilt, sympathy-pity, and positive emotions did not reveal any significant key three-way interactions (all $p \mathrm{~s}>.072$ ). For space considerations, we relegate these tables to SOM (Tables S19-S23). Findings of note were a main effect of social 
conservatism on political intolerance not moderated by higher-order effects, and a Social Ideology $\times$ Orientation interaction on negative traits suggesting that social liberals assigned more negative traits to right-wing than left-wing groups, whereas there was no bias among social conservatives (inconsistent with the social-specific asymmetry hypothesis).

Testing the social primacy hypothesis. To formally test the social primacy hypothesis, we compared the absolute values of the regression coefficients associated with the key three-way interactions through model constraint in Mplus 7. Of the models that yielded significant Social Ideology $\times$ Orientation $\times$ Dimension and/or Economic Ideology $\times$ Orientation $\times$ Dimension interactions, worldview conflict (Wald $\chi^{2}=5.31, d f=1, p=.021$ ), negative assessment (Wald $\chi^{2}$ $=2.61, d f=1, p=.106)$, and the negative emotion factor (Wald $\chi^{2}=5.12, d f=1, p=.024$ ) were consistent with the social primacy hypothesis, although the effect only approached significance for negative assessment. There was no support for the social primacy hypothesis on either warmth or competence traits $(p s>.399)$.

Testing mediation via worldview conflict. Using Mplus 7, we performed a path analysis to examine the indirect effects of the Social Ideology $\times$ Orientation $\times$ Dimension and Economic Ideology $\times$ Orientation $\times$ Dimension interactions on negative assessment, warmth traits, competence traits, and negative emotions via worldview conflict. These four outcome variables were specified as separate outcomes, worldview conflict as the mediator, and all variables and interaction terms from the moderated multiple regression analyses as independent variables. For each of these four outcome variables, the indirect effect of the Social Ideology $\times$ Orientation $\times$ Dimension interaction via worldview conflict was significant (negative assessment: $b=.30, S E=$ $.09,95 \%$ CIs $[.13, .46], p<.001$; warmth traits: $b=-1.82, S E=.55,95 \%$ CIs $[-2.91,-.74], p<$ .001 ; competence traits: $b=-1.37, S E=.43,95 \%$ CIs [-2.21, -.53], $p<.001$; negative emotion: $b$ 
$=.26, S E=.08,95 \%$ CIs $[.11, .41], p<.001)$. However, the indirect effects of the Economic Ideology $\times$ Orientation $\times$ Dimension interaction via worldview conflict approached, but never reached, significance (negative assessment: $b=-.13, S E=.08,95 \%$ CIs $[-.29, .03], p=.114$; warmth traits: $b=.80, S E=.51,95 \%$ CIs $[-.20,1.80], p=.117$; competence traits: $b=.60, S E=$ $.39,95 \%$ CIs $[-.16,1.36], p=.120$; negative emotion: $b=-.12, S E=.07,95 \%$ CIs $[-.26, .03], p=$ $.115)$.

\section{Discussion}

In Study 5, we sought to extend tests of the three hypotheses to additional measures of prejudice, alternative measures of social and economic ideology, and targets who were distinguished solely on the basis of political orientation and dimension. First, we essentially replicated findings from the previous studies using alternative social and economic ideology measures and alternative targets, as results revealed support for the dimension-specific symmetry and mixed support for the social primacy hypotheses on the general negative assessment measure, which contained the feeling thermometer and social distance measures used in our previous studies. Further, consistent with our previous studies, the Social Ideology $\times$ Orientation $\times$ Dimension effect on general negative assessment was mediated by worldview conflict. There was also no support for the social-specific asymmetry hypothesis on any of outcome measures.

We found either full or mixed support for the dimension-specific and social primacy hypotheses on some but not all of the additional outcome variables. Specifically, some level of support for these two hypotheses was observed for aspects of prejudice related to stereotypes and beliefs (i.e., warmth and competence trait attributions) and on generally negative emotional reactions. However, the results also suggest some limitations to what sorts of group perceptions, intentions, and beliefs will elicit dimension-specific reactions, as there was no support for any of 
the three hypotheses on political intolerance, negative traits, and complex (sympathy/pity, anxiety-fear/envy-guilt) and positive emotions. That said, Table S22 shows that sympathy-pity was only weakly related to worldview conflict, suggesting it may not be relevant for ideological prejudice.

\section{General Discussion}

Several recent studies consistent with the ideological conflict hypothesis (Brandt et al., 2014) found that both liberals and conservatives express prejudice toward ideologically dissimilar others, and to relatively equal degrees. Other recent evidence shows that ideology is multi-dimensional, with social and economic ideologies representing related but distinct belief systems (Carmines \& D’Amico, 2015; Feldman \& Johnston, 2014; Malka \& Soto, 2015). In five studies (total $N=4912$ ), we tested three hypotheses of a multi-dimensional account of ideological prejudice. The dimension-specific symmetry hypothesis predicts that social and economic ideologies differentially predict prejudice against targets perceived on the social and economic political dimensions, respectively. The social primacy hypothesis predicts that ideological worldview conflict is experienced more strongly along the social than economic dimension, consistent with findings that the social dimension appears to inspire more political conflict than the economic dimension in the United States (Graham et al., 2009; Hare \& Poole,

2014; Malka et al., 2014). The social-specific hypothesis predicts that social conservatives will be more prejudiced than social liberals, consistent with findings that social conservatism is especially related to needs for certainty and closure, which are often associated with prejudice and intergroup bias (e.g., van Hiel et al., 2004). 
We conducted both between-subjects (Studies 2, 4, and 5) and within-subjects (Studies 1 and 3) tests of our hypotheses. ${ }^{11}$ Study 1 examined the relationships of participant social and economic ideology with prejudice toward a heterogeneous array of 78 different target groups that varied in their perceived social and economic liberalism and conservatism. Study 2 examined explicit prejudice toward an exemplar of each different group type in the orientation (liberal vs. conservative) $\times$ dimension (social vs. economic) space, and whether dimension-specific effects of ideology on prejudice were partly explained by worldview conflict. Study 3 examined both explicit attitudes toward and automatic associations with these target groups. Study 4 used a dictator game to explore the dimension-specific effects of ideology on discriminatory behavior toward individual members of these target groups. Study 5 extended these findings to additional measures of prejudice and alternative measures of political ideology, and removed the social group content of the targets that was embedded within Studies 1-4.

Table 6 summarizes support observed for the three hypotheses. The dimension-specific symmetry hypothesis received the most support, with 16 of 21 tests providing full or mixed support. Social ideology better predicted attitudes toward targets that varied on the social dimension, whereas economic ideology better predicted attitudes toward targets that varied on the economic dimension; and social and economic liberals tended to be biased against social and economic conservatives, respectively, whereas social and economic conservatives tended to be biased against social and economic liberals, respectively. These findings reaffirm the importance of a multi-dimensional approach to political ideology in general, and are the first to demonstrate that the distinction between social and economic political ideologies also extends to intergroup attitudes and behavior on both sides of the political spectrum.

\footnotetext{
${ }^{11}$ Within-subjects designs may underestimate effects of political biases (Crawford, Kay, \& Duke, 2015).
} 
All five tests that provided no support for the dimension-specific hypothesis were observed in Study 5, which sought to extend the hypothesis to additional prejudice measures, more generic socially and economically liberal/conservative targets, and using issue positions rather than self-identification to measure ideology. The findings extended well to negative assessments and emotions and to decreased attributions of positive traits (warmth, competence), but less so to complex emotional reactions, positive emotions, negative traits, and behavioral intentions toward political intolerance (although note that support for the hypothesis was found on social distance intentions throughout these studies, and on actual behavior in Study 4). Importantly, Study 5 replicated the previous findings that worldview conflict in part explained support for the dimension-specific hypothesis, at least on the social dimension (consistent with the social primacy hypothesis, effects were stronger on the social than economic dimension).

The strongest support for the social primacy hypothesis came from Studies 2 and 3, which observed some level of support on all five outcomes. Study 4 revealed no significant support for the social primacy hypothesis, although the effects trended in the predicted direction on worldview conflict and prejudice in this smaller sample. In Study 5, it received some support on all five outcomes for which the dimension-specific hypothesis also received some support, but no support on the other five outcomes. No support for the social primacy hypothesis emerged in Study 1, although collapsing across multiple targets may have masked support for the hypothesis compared to Studies 2-4, which used more carefully chosen target groups. A re-analysis of Study 1's data focusing on the targets used in Studies 2-4 supports this possibility. None of the three samples from Study 1 included all four targets from Studies 2-4 (i.e., Evangelicals, atheists, welfare recipients, rich people), but Sample 1 included rich people, welfare recipients, and atheists, and Sample 3 included rich people, welfare recipients, and Evangelical Christians. 
Focusing solely on these targets, we found support for the social primacy hypothesis in both samples, as the effects of social ideology on prejudice toward the social targets were stronger than those of economic ideology on prejudice toward economic targets, in all possible comparisons (all Wald $\chi \mathrm{s}>9.69$, all $p \mathrm{~s}<.002$ ). These results, along with the mixed support in Study 5 using generic targets, suggest some caution in generalizing support for the social primacy hypothesis to all possible social and economic targets. That said, recall that the targets used in Studies 2-4 were chosen because they were perceived as being clearly related to one dimension more than the other (Sample 4, Study 1). Tables S1 and S2 also show that in Study 1, economic ideology was a strong predictor of prejudice toward these groups (Sample 1: rich people $\mathrm{B}=-.49$; welfare recipients $\mathrm{B}=.52$ ). Thus, these targets should have been particularly divisive for economically liberal and conservative participants. Thus, political conflict and its resulting negative intergroup consequences appear in some cases more deeply felt along the social than economic dimension, consistent with suggestions in the literature (Graham et al., 2009; Hare \& Poole, 2014; Malka et al., 2014) and among social commentators (Hunter, 1991) that the conflicts that most deeply divide Americans are those fought along social rather than economic issues.

Finally, the social-specific asymmetry hypothesis received no support in any tests. Thus, despite the fact that personality traits associated with prejudice are often associated with social conservatism (e.g., van Hiel et al., 2004), results across these five studies showed that social conservatives were not uniquely biased.

Across Studies 2-5, there was ample support for the prediction, derived from the ideological conflict hypothesis, that worldview conflict in part explains the relationship between ideology and intergroup attitudes. Interaction effects on worldview conflict emerged in each of 
those studies, indicating that political prejudice is dimension-specific - that is, people notice conflicts over beliefs and values that parse between differences on the social and economic ideological dimensions, and those perceived value conflicts in part explain negative intergroup reactions. At the same time, these value differences appear more deeply felt along the social dimension, as effects on worldview conflict were larger on social than economic dissimilarity in Studies 2, 3, and 5 .

Support for the dimension-specific symmetry and social primacy hypotheses is inconsistent with perspectives that emphasize a unidimensional over a multidimensional approach to political ideology (e.g., Jost, 2006; Sterling, Jost, \& Pennycock, 2016). The present results contribute to a growing literature suggesting that social and economic ideologies have distinct psychological correlates (Duckitt \& Sibley, 2010; Feldman \& Johnston, 2014; Malka \& Soto, 2015) and that voters clearly consider social and economic issues differently (Feldman \& Johnston, 2014; Johnston \& Wronski, 2015). In contrast to the dual process motivational model of prejudice (Duckitt \& Sibley, 2010), the present findings extend ideology-based prejudice to groups across the political spectrum, identify dimension-specific worldview conflict as an important motivation for prejudice, and offer predictions regarding the relative importance of the social dimension that the dual process model does not predict. Indeed, the ascendance of Donald Trump to the U.S. Presidency on appeals to racism, sexism, and xenophobia (e.g., O'Connor, 2016), and the fact that he can hardly be classified as liberal or conservative based on his policy proposals, highlight the importance of understanding how ideologically complex beliefs influence intergroup attitudes. 
To add to the growing literature on person-level differences in social and economic ideologies, we present relationships between demographic characteristics and social and economic ideologies in Table S24. Although there was variation across samples, men appeared higher than women in economic conservatism, whereas gender differences in social ideology rarely emerged. There appeared few age differences, save for results in Study 5 suggesting that older people are more conservative. Whiteness, education, and SES (as well as income; Study 5) were fairly consistently associated with economic conservatism but also social liberalism. (And as noted, support for the dimension-specific and social primacy hypotheses largely held while controlling for demographic variables). These findings are consistent with other findings regarding how social and economic ideologies are differentially related to important sociodemographic characteristics (Feldman \& Johnston, 2014).

\section{Future Directions}

Although we utilized different sample sources (Mechanical Turk; YourMorals; college students), none were nationally representative samples. Future research could test these and other hypotheses about the multi-dimensional nature of political conflict with nationally representative samples. Further, whereas Study 1 examined a broad array of targets, Studies $2-4$ focused on the (relatively) same four targets. Given the support for the social primacy hypothesis in Studies 2-4 but not Study 1, future studies could examine different targets than those used in these studies. That said, Study 5 attempted to rectify this issue by using targets without reference to particular social groups, and found support for the social primacy hypothesis on several (although not all) relevant variables.

These studies showed that worldview conflict is a strong driver of political prejudice, but not necessarily discrimination (Study 4) or some behavioral intentions (political intolerance, 
Study 5; but see support on social distance in Studies 2 - 5). Future work could examine whether different types of threat drive multi-dimensional accounts of prejudice and discrimination, and further, whether different dimensions are characterized by different types of threat (e.g., symbolic for social targets; realistic for economic targets). Further, the finding that social issues appear to involve more hostility than economic issues, and that they are "easier" issues (Carmines \& Stimson, 1980), suggest that people may have more emotionally visceral experiences with social than economic issues, or that these issues are more closely tied to disgust than economic issues (for relevant evidence, see Crawford, Inbar, \& Maloney, 2014). Future research could explore these possibilities.

One potential caveat to the worldview conflict findings is that in Studies 2, 4, and 5, the item asked about differences in "political and social beliefs." Thus, one could argue that worldview conflict was stronger on social than economic issues because "social beliefs" were mentioned in the worldview conflict item. This is certainly a possibility, although the fact that economic ideology more strongly predicted worldview conflict with economic targets than social ideology (e.g., Study 3) suggests the findings are robust to this interpretation.

We adopt an approach to studying prejudice that allows for prejudice to be expressed toward any group, by any individual or group, regardless of whether that group is historically disadvantaged or not. This approach is consistent with other theoretical and empirical approaches in prejudice research (e.g., Aronson et al., 2010; Crandall et al., 2002), and is useful because it can illuminate the psychology of prejudice as it is broadly understood. This helps us understand if the psychological processes and individual differences underlying prejudice are similar or different across a range of target groups. That said, this approach, as well as many others in social psychology, tell us nothing about whether the expression of prejudice toward some groups 
but not others is justified or unjustified. Capturing whether a prejudice is justified or not is notoriously difficult because one person's well-justified prejudice is another person's poorly conceived justification for prejudice. This is also a challenge that social psychologists have typically ignored (see Crandall et al., 2002; Crandall, Ferguson, \& Bahns, 2013 for a discussion). One way to assess if the prejudices are different is if expressions of prejudice against targets is experienced differently. It may be that some types of prejudice are more harmful than others; or, that some groups possess social identities or material resources that help buffer expressed prejudice. Future empirical work could therefore help determine the weight of prejudice on groups and individuals, and inform the moral weight society should feel at its expression.

Although the types of economic targets varied slightly by study, the fact that several effects were more robust on the social compared to the economic dimension suggests that there is not something unique to the targets we chose for Studies $2-4$ that dampened effects (and as Study 4 showed, these economic targets could inspire discrimination). This argument is also bolstered by results of Study 5 showing some support for the social primacy hypothesis using generic economically liberal and conservative targets. An inspection of Tables S1 and S2 suggests that there are simply more targets of prejudice to choose from when one thinks of groups for whom one differs on social issues than on economic issues. Specifically, whereas there are roughly 7 liberal (Table S1) and 8 conservative (Table S2) targets for whom social ideology appears a stronger predictor than economic ideology, there are only 4 liberal targets and 1 conservative target for whom economic ideology appears a stronger predictor than social ideology. While this state of affairs may reflect the imaginations of those who constructed these survey materials (recall that none of the samples in Study 1 were constructed with the socialeconomic distinction in mind), it may also be further evidence in support for the social primacy 
hypothesis. First, survey researchers may choose more social than economic groups for inclusion because they are aware of the greater divisiveness of sociocultural than economic issues in American politics. Second, there may simply be a broader array of social compared to economic groups, with such diversity reflecting more avenues for conflict. Future research should attempt to include a greater variety of economic targets in order to address this issue.

\section{Conclusion}

In five studies using a diversity of methods and of measures of prejudice, we tested three distinct but not necessarily mutually exclusive hypotheses regarding the multi-dimensionality of ideological conflict in the United States. Generally, we found support for the dimension-specific symmetry hypothesis, indicating that people's social and economic ideologies predict prejudice and discrimination toward targets who vary on the social and economic political dimensions, respectively. At the same time, however, we also found fairly consistent support for the social primacy hypothesis, indicating that such dimension-specific worldview conflict is expressed more strongly along the social than economic dimension. Together, these results suggest that ideological conflict in the United States is deeply-felt, and also dimension-specific. They also suggest that interventions in political conflict should focus primarily on the kinds of issues that divide Americans along sociocultural issues. Of course, given how strongly those issues are tied to worldview conflict, this remains a daunting challenge. 


\section{References}

Aiken, L. S., \& West, S. G. (1991). Multiple regression: Testing and interpreting interactions. Newbury Park, CA: Sage.

Allport, G. W. (1954). The nature of prejudice. Reading, MA: Addison-Wesley.

Altemeyer, B. (1998). The other "authoritarian personality". In M. P. Zanna (Ed.), Advances in experimental social psychology (Vol. 30, pp. 47-91). New York, NY: Academic Press.

Aronson, E., Wilson, T. D., \& Akert, R. M. (2010). Social Psychology (7 $\left.{ }^{\text {th }}\right)$. New York: Prentice Hall.

Bendersky, C. (2014). Resolving ideological conflicts by affirming opponents'status: The Tea Party, Obamacare and the 2013 government shutdown. Journal of Experimental Social Psychology, 53, 163-168.

Blanton, H., Jaccard, J., Strauts, E., Mitchell, G., \& Tetlock, P. E. (2015). Toward a meaningful metric of implicit prejudice. Journal of Applied Psychology. http://dx.doi.org/10.1037/a0038379

Bogardus, E. S. (1933). A social distance scale. Sociology \& Social Research, 17, 265-271. Brandt, M. J., Chambers, J. R., Crawford, J. T., Wetherell, G., \& Reyna, C. (2015). Bounded openness: The effect of openness to experience on intolerance is moderated by target group conventionality. Journal of Personality and Social Psychology, 109, 549-568.

Brandt, M. J., \& Reyna, C. (2014). To love or hate thy neighbor: The role of core motives in explaining the link between fundamentalism and racial prejudice. Political Psychology, $35,207-223$.

Brandt, M. J., Reyna, C., Chambers, J. R., Crawford, J. T., \& Wetherell, G. (2014). The ideological-conflict hypothesis: Intolerance among both liberals and conservatives. Current Directions in Psychological Science, 23, 27-34. 
Brandt, M. J., \& Van Tongeren, D. R. (in press). Both high and low on religious fundamentalism are prejudiced towards dissimilar groups. Journal of Personality and Social Psychology.

Brown, R. (2010). Prejudice: Its Social Psychology (2nd ed.). Malden, MA: Wiley-Blackwell.

Byrne, D. (1971). The attraction paradigm. New York, NY: Academic Press.

Carmines, E.G., \& D’Amico, N. J. (2015). The new look in political ideology research. Annual Review of Political Science, 18, 205-216.

Carmines, E. G., Ensley, M. J., \& Wagner, M. W. (2012). Political ideology in American politics: One, two, or none? Forum, 10, 1-18

Carmines, E. G., \& Stimson, J. A. (1980). The two faces of issue voting. The American Political Science Review, 74, 78-91.

Chambers, J. R., Schlenker, B. R., \& Collisson, B. (2013). Ideology and prejudice: The role of value conflicts. Psychological Science, 24, 140-149.

Clifford, S., Jewell, R. M., \& Waggoner, P. D. (2015). Are samples drawn from Mechanical Turk valid for research on political ideology?. Research \& Politics, 2(4), 2053168015622072.

Correll, J., Judd, C. M., Park, B., \& Wittenbrink, B. (2010). Measuring prejudice, stereotypes and discrimination. In J. F. Dovidio, M. Hewstone, P. Glick, \& V. M. Esses (Eds.), The SAGE Handbook of Prejudice, Stereotyping and Discrimination (pp. 45-62). Thousand Oaks, CA: SAGE.

Cottrell, C. A., \& Neuberg, S. L. (2005). Different emotional reactions to different groups: A sociofunctional threat-based approach to "prejudice". Journal of Personality and Social Psychology, 88, 770-789. 
Crandall, C. S., Eshleman, A., \& O’Brien, L. (2002). Social norms and the expression and suppression of prejudice: The struggle for internalization. Journal of Personality and Social Psychology, 82, 359-378.

Crandall, C. S., Ferguson, M. A., \& Bahns, A. J. (2013). When we see prejudice: The normative window and social change. In C. Stangor, \& C. S. Crandall (Eds.), Frontiers in stereotyping and prejudice. (pp. 53-70). New York, NY: Psychology Press.

Crawford, J. T. (2014). Ideological symmetries and asymmetries in political intolerance and prejudice toward political activist groups. Journal of Experimental Social Psychology, 55, 284-298.

Crawford, J. T., Brandt, M. J., Inbar, Y., \& Mallinas, S. R. (2016). Right-wing authoritarianism predicts prejudice equally toward "gay men and lesbians" and "homosexuals." Journal of Personality and Social Psychology, 111, e31-e45.

Crawford, J. T., Inbar, Y., \& Maloney, V. (2014). Disgust sensitivity selectively predicts attitudes toward groups that threaten (or uphold) traditional sexual morality. Personality and Individual Differences, 70, 218-223.

Crawford, J. T., Kay, S., \& Duke, K. E. (2015). Speaking out of both sides of their mouths: Biased political judgments within (and between) individuals. Social Psychological and Personality Science, 6, 422-430.

Crawford, J. T., Mallinas, S. R., \& Furman, B. J. (2015). The balanced ideological antipathy model: Explaining the effects of ideological attitudes on intergroup antipathy across the political spectrum. Personality and Social Psychology Bulletin, 41, 1607-1622.

Crawford, J. T., \& Pilanski, J. M. (2014). Political intolerance, right and left. Political Psychology, 35, 841-851. 
Cuddy, A. C., Fiske, S. T., \& Glick, P. (2007). The BIAS map: Behaviors from intergroup affect and stereotypes. Journal of Personality and Social Psychology, 92(4), 631-648.

Cunningham, W. A., Nezlek, J. B., \& Banaji, M. R. (2004). Implicit and explicit ethnocentrism: Revisiting ideologies of prejudice. Personality and Social Psychology Bulletin, 30, 13321346.

Duckitt, J., \& Fisher, K. (2003). The impact of social threat on worldview and ideological attitudes. Political Psychology, 24, 199-222.

Duckitt, J., \& Sibley, C. G. (2007). Right wing authoritarianism, social dominance orientation and the dimensions of generalized prejudice. European Journal of Personality, 21(2), 113-130.

Duckitt, J., \& Sibley, C. G. (2010). Personality, ideology, prejudice, and politics: A dual process motivational model. Journal of Personality, 78, 1861-1893.

Ellis, C., \& Stimson, J.A. (2012). Ideology in America. New York: Cambridge University Press.

Feldman, S., \& Johnston, C. (2014). Understanding the determinants of political ideology: Implications of structural complexity. Political Psychology, 35, 337-358.

Fershtman, C., \& Gneezy, R (2001). Discrimination in a segmented society: An experimental approach. The Quarterly Journal of Economics, 116, 351-377.

Fiske, S. T., Cuddy, A. J., Glick, P., \& Xu, J. (2002). A model of (often mixed) stereotype content: competence and warmth respectively follow from perceived status and competition. Journal of Personality and Social Psychology, 82, 878-902.

Flynn, F. J. (2005). Having an open mind: The impact of openness to experience on interracial attitudes and impression formation. Journal of Personality and Social Psychology, 88, 816-826. 
Gift, K., \& Gift, T. (2015). Does politics influence hiring? Evidence from a randomized experiment. Political Behavior, 37, 653-675.

Graham, J., Haidt, J., \& Nosek, B. A. (2009). Liberals and conservatives rely on different sets of moral foundations. Journal of Personality and Social Psychology, 96, 1029-1046.

Greenwald, A. G., McGhee, D. E., \& Schwartz, J. L. K. (1998). Measuring individual differences in implicit cognition: The Implicit Association Test. Journal of Personality and Social Personality, 74(6), 1464-1480.

Greenwald, A. G., Nosek, B. A., \& Banaji, M. R. (2003). Understanding and using the Implicit Association Test: I. An improved scoring algorithm. Journal of Personality and Social Psychology, 85, 197-216.

Hare, C., \& Poole, K. T. (2014). The polarization of contemporary American politics. Polity, 46, 411-429.

Hibbing, J. R., Smith, K. B., \& Alford, J. R. (2014). Differences in negativity bias underlie variations in political ideology. Behavioral \& Brain Sciences, 37, 297-350.

Hodson, G., Hogg, S. M., \& MacInnis, C. C. (2009). The role of "dark personalities" (narcissism, Machiavellianism, psychopathy), Big Five personality factors, and ideology in explaining prejudice. Journal of Research in Personality, 43(4), 686-690.

Hunter, J. D. (1991). Culture wars: The struggle to define America. New York: Basic Books. Iyengar, S., \& Westwood, S. J. (2014). Fear and loathing across party lines: New evidence on group polarization. American Journal of Political Science, 59, 690-707.

Johnston, C. D., \& Wronski, J. (2015). Personality dispositions and political preferences across hard and easy issues. Political Psychology, 36, 35-53.

Jost, J. T. (2006). The end of the end of ideology. American Psychologist, 61(7), 651-670. 
Jost, J. T., Glaser, J., Kruglanski, A. W., \& Sulloway, F. J. (2003). Political conservatism as motivated social cognition. Psychological Bulletin, 129, 339-375.

Jost, J. T., \& Krochik, M. (2014). Ideological differences in epistemic motivation: implications for attitude structure, depth of information processing, susceptibility to persuasion, and stereotyping. Advances in Motivation Science, 1, 181-231.

Jost, J. T., Nosek, B. A., \& Gosling, S. D. (2008). Ideology: Its resurgence in social, personality, and political psychology. Perspectives on Psychological Science, 3, 126-136.

Jost, J. T., \& Thompson, E. P. (2000). Group-based dominance and opposition to equality as independent predictors of self-esteem, ethnocentrism, and social policy attitudes among African Americans and European Americans. Journal of Experimental Social Psychology, 36, 209-232.

Koleva, S. P., Graham, J., Iyer, R., Ditto, P. H., \& Haidt, J. (2012). Tracing the threads: How five moral concerns (especially Purity) help explain culture war attitudes. Journal of Research in Personality, 46(2), 184-194.

Malka, A., \& Soto, C. J. (2015). Rigidity of the economic right? Menu-independent and menudependent influences of psychological dispositions. Current Directions in Psychological Science, 24, 137-142.

Malka, A., Soto, C. J., Inzlicht, M., \& Lelkes, Y. (2014). Do needs for security and certainty predict cultural and economic conservatism? A cross-national analysis. Journal of Personality and Social Psychology, 106, 1031-1051.

Mason, W. (2011). Open-source, Web-based IAT. Retrieved from http://github.com/winteram/IAT. 
Muthén, L. K., \& Muthén, B. O. (1998-2012). Mplus User’s guide. Seventh Edition. Los Angeles, CA: Muthén \& Muthén.

Nosek, B. A. (2005). Moderators of the relationship between implicit and explicit evaluation. Journal of Experimental Psychology: General, 134, 565-584.

Nosek, B. A. (2007). Implicit-explicit relations. Current Directions in Psychological Science, 16(2), 65-69.

Nosek, B. A., Greenwald, A. G., \& Banaji, M. R. (2005). Understanding and using the Implicit Association Test: II. Method variables and construct validity. Personality and Social Psychology Bulletin, 31, 166-180.

Olson, M. A., Crawford, M. T., Devlin, W. (2009). Evidence for the underestimation of implicit in-group favoritism among low-status groups. Journal of Experimental Social Psychology, 45, 1111-1116.

O’Connor, L. (2016). Here are 13 examples of Donald Trump being racist. Retrieved November 21, 2016 from http://www.huffingtonpost.com/entry/donald-trump-racistexamples_us_56d47177e4b03260bf777e83

Rand, D. G., Pfeiffer, T., Dreber, A., Sheketoff, R. W., Wernerfelt, N. C., \& Benkler, Y. (2009). Dynamic remodeling of in-group bias during the 2008 Presidential election. Proceedings of the National Academy of Sciences, 106, 6187-6191.

Roets, A., \& Van Hiel, A. (2011). Allport's prejudiced personality today: Need for closure as the motivated cognitive basis of prejudice. Current Directions in Psychological Science, 20, 349-354.

Rokeach, M. (1973). The nature of human values. New York, NY: Free Press. 
Rudman, L. A., Greenwald, A. G., \& McGhee, D. E. (2001). Implicit self-concept and evaluative implicit gender stereotypes: Self and ingroup share desirable traits. Personality and Social Psychology Bulletin, 27(9), 1164-1178.

Schwartz, S.H. (1992). Universals in the content and structure of values: theoretical advances and empirical tests in 20 countries. Advances in experimental social psychology, 25, 1-65

Schwartz, S. H., Caprara, G. V., \& Vecchione, M. (2010). Basic personal values, core political values, and voting: A longitudinal analysis. Political Psychology, 31, 421-452.

Sibley, C. G., \& Duckitt, J. (2008). Personality and prejudice: A meta-analysis and theoretical review. Personality and Social Psychology Review, 12, 248-279.

Sibley, C. G., Wilson, M. S., \& Duckitt, J. (2007). Antecedents of men's hostile and benevolent sexism: The dual roles of social dominance orientation and right-wing authoritarianism. Personality and Social Psychology Bulletin, 33, 160-172.

Sidanius, J., \& Pratto, F. (1999). Social dominance: An intergroup theory of social hierarchy and oppression. New York: Cambridge University Press.

Simonsohn, U. (2015). Small telescopes: Detectability and the evaluation of replication results. Psychological Science, 26, 559-569.

Skitka, L. J., Liu, J. H., Yang, Y., Chen, H., Liu, L., \& Xu, L. (2013). Exploring the crosscultural generalizability and scope of morally motivated intolerance. Social Psychological and Personality Science, 4, 324-331.

Sterling, J., Jost, J.T., \& Pennycock, G. (2016). Are neoliberals more susceptible to bullshit? Judgment and Decision-Making, 11, 352-360. 
Terrizzi Jr, J. A., Shook, N. J., \& Ventis, W. L. (2010). Disgust: A predictor of social conservatism and prejudicial attitudes toward homosexuals. Personality and Individual Differences, 49(6), 587-592.

van Osch, Y. M., \& Breugelmans, S. M. (2012). Perceived intergroup difference as an organizing principle of intercultural attitudes and acculturation attitudes. Journal of Cross-Cultural Psychology, 43, 801-821.

Van Hiel, A., Pandelaere, M., \& Duriez, B. (2004). The impact of need for closure on conservative beliefs and racism: Differential mediation by authoritarian submission and authoritarian dominance. Personality and Social Psychology Bulletin, 30, 824-837.

Van Prooijen, J. W., Krouwel, A. P. M., Boiten, M., \& Eendebak, L. (2015). Fear among the extremes: How political ideology predicts negative emotions and outgroup derogation. Personality and Social Psychology Bulletin, 41, 485-497.

Waytz, A., Young, L. L., \& Ginges, J. (2014). Motive attribution asymmetry for love vs. hate drives intractable conflict. Proceedings of the National Academy of Sciences, 111, 1568715692.

Wetherell, G. A., Brandt, M. J., \& Reyna, C. (2013). Discrimination across the ideological divide: The role of value violations and abstract values in discrimination by liberals and conservatives. Social Psychological and Personality Science, 4, 658-667.

Wright, J. C., Cullum, J., \& Schwab, N. (2008). The cognitive and affective dimensions of moral conviction: Implications for attitudinal and behavioral measures of interpersonal tolerance. Personality and Social Psychology Bulletin, 34, 1461-1476. 
Table 1

Study 1: Multi-level models for the three samples

\begin{tabular}{|c|c|c|c|c|}
\hline & \multicolumn{3}{|c|}{ Sample 1} & \multirow[b]{2}{*}{$95 \% \mathrm{CI}$} \\
\hline & $b$ & $S E$ & $t$ & \\
\hline Constant & 3.96 & .01 & $418.49 * * *$ & $3.93,3.98$ \\
\hline Social & .07 & .004 & $16.05 * * *$ & $.06, .08$ \\
\hline Econ & .08 & .004 & $18.32 * * *$ & $.07, .08$ \\
\hline Perceived social & -.47 & .03 & $-16.06 * * *$ & $-.53,-.41$ \\
\hline Perceived econ & .38 & .03 & $12.19 * * *$ & $.32, .44$ \\
\hline Social $\mathrm{x}$ perceived social & -.41 & .01 & $-30.28 * * *$ & $-.44,-.39$ \\
\hline Social x perceived econ & .24 & .01 & $17.05^{* * *}$ & $.22, .27$ \\
\hline Econ $\mathrm{x}$ perceived social & .29 & .01 & $22.29 * * *$ & $.26,31$ \\
\hline Econ $\mathrm{x}$ perceived econ & -.47 & .01 & $-34.75^{* * *}$ & $-.50,-.45$ \\
\hline \multicolumn{5}{|c|}{ Sample 2} \\
\hline Constant & 51.20 & .99 & $51.80 * * *$ & $49.25,53.14$ \\
\hline Social & -.49 & .70 & -.71 & $-1.88, .89$ \\
\hline Econ & 1.09 & .72 & 1.51 & $-.33,2.51$ \\
\hline Perceived social & 7.61 & 2.85 & $2.67 * * *$ & $1.99,13.23$ \\
\hline Perceived econ & -5.95 & 2.87 & $-2.07 * *$ & $-11.61,-.28$ \\
\hline Social x perceived social & -8.70 & 2.03 & $-4.29 * * *$ & $-12.70,-4.70$ \\
\hline Social x perceived econ & 4.83 & 2.05 & $2.37^{*}$ & $.80,8.86$ \\
\hline Econ $\mathrm{x}$ perceived social & 7.85 & 2.07 & $3.78 * * *$ & $3.76,11.93$ \\
\hline Econ $\mathrm{x}$ perceived econ & -10.99 & 2.09 & $-5.26 * * *$ & $-15.11,-6.88$ \\
\hline \multicolumn{5}{|c|}{ Sample 3} \\
\hline Constant & 45.25 & 1.20 & $37.66 * * *$ & $42.88,47.61$ \\
\hline Social & .63 & .77 & .84 & $-.84,2.10$ \\
\hline Econ & .90 & .74 & 1.22 & $-.56,2.35$ \\
\hline Perceived social & 8.41 & 1.88 & $4.47 * * *$ & $4.69,12.12$ \\
\hline Perceived econ & -8.46 & 1.96 & $-4.32 * * *$ & $-12.32,-4.60$ \\
\hline Social x perceived social & -6.89 & 1.17 & $-5.90 * * *$ & $-9.19,-4.59$ \\
\hline Social x perceived econ & 4.10 & 1.21 & $3.83 * *$ & $1.71,6.49$ \\
\hline Econ $\mathrm{x}$ perceived social & 4.23 & 1.16 & $3.66^{* * *}$ & $1.95,6.51$ \\
\hline Econ $\mathrm{x}$ perceived econ & -5.96 & 1.20 & $-4.97 * * *$ & $-8.33,-3.60$ \\
\hline
\end{tabular}

$* p<.05 ; * * p<.01 ; * * * p<.001$ 
Table 2

Study 2: moderated multiple regression analysis on worldview conflict and prejudice (Step 3 only)

\begin{tabular}{|c|c|c|c|c|c|c|c|c|}
\hline & \multicolumn{3}{|c|}{$\begin{array}{c}\text { Worldview } \\
\text { Conflict }\end{array}$} & \multicolumn{5}{|c|}{ Prejudice } \\
\hline & $b$ & $S E$ & $t$ & $95 \%$ CI & $b$ & $S E$ & $t$ & $95 \% \mathrm{CI}$ \\
\hline Constant & 2.97 & 0.22 & $13.5^{* * *}$ & $2.53,3.40$ & .38 & 0.04 & $9.23^{* * *}$ & $.31, .46$ \\
\hline Social ideology & .55 & 0.15 & $3.65 * * *$ & $.25, .84$ & .08 & 0.02 & $3.58 * * *$ & $.04, .12$ \\
\hline Economic ideology & 0.25 & 0.13 & 1.91 & $-.01, .50$ & 0.02 & 0.02 & 1.03 & $-.02, .07$ \\
\hline Orientation $(\mathrm{O})$ & 2.29 & 0.30 & $7.51 * * *$ & $1.69,2.89$ & 0.08 & 0.05 & 1.40 & $-.03, .18$ \\
\hline Dimension (D) & .89 & 0.31 & $2.89 * *$ & $.28,1.50$ & 0.06 & 0.06 & 0.99 & $-.06, .17$ \\
\hline Social X O & -1.32 & 0.21 & $-6.19 * * *$ & $-1.74,-.90$ & -.15 & 0.03 & $-4.88 * * *$ & $-.21,-.09$ \\
\hline Economic X O & -0.20 & 0.20 & -1.02 & $-.59, .19$ & -0.06 & 0.03 & -1.68 & $-.12, .01$ \\
\hline Social X D & -0.43 & 0.25 & -1.71 & $-.92, .07$ & -.08 & 0.04 & $-2.23^{*}$ & $-.15,-.01$ \\
\hline Economic X D & 0.08 & 0.23 & 0.33 & $-.38, .53$ & 0.03 & 0.04 & 0.64 & $-.05, .10$ \\
\hline Social X Economic & 0.01 & 0.06 & 0.15 & $-.10, .12$ & 0.01 & 0.01 & 0.52 & $-.01, .02$ \\
\hline OX D & -.93 & 0.39 & $-2.37 *$ & $-1.70,-.16$ & -0.02 & 0.07 & -0.24 & $-.16, .13$ \\
\hline Social X O X D & 1.47 & 0.34 & $4.36^{* * *}$ & $.81,2.13$ & .17 & 0.05 & $3.46^{* * *}$ & $.08, .27$ \\
\hline Economic X O X D & -.58 & 0.34 & $-1.71 \dagger$ & $-1.24, .09$ & -0.05 & 0.05 & -1.07 & $-.15, .05$ \\
\hline Social X Economic X O & -0.04 & 0.07 & 0.16 & $-.14, .16$ & -0.01 & 0.01 & -0.26 & $-.03, .02$ \\
\hline Social X Economic X D & 0.01 & 0.08 & -0.53 & $-.18, .11$ & -0.02 & 0.01 & -1.75 & $-.04, .01$ \\
\hline
\end{tabular}

$\dagger p<.10 ; * p<.05 ; * * p<.01 ; * * * p<.001$ 
Multi-Dimensional Ideological Conflict 74

Table 3

Study 4: Moderated multiple regression analysis on worldview conflict, prejudice, and ticket allocation (Step 3 only)

\begin{tabular}{|c|c|c|c|c|c|c|c|c|c|c|c|c|}
\hline & & Worldview & Conflict & & & rejudic & & & & Ticket & Allocation & \\
\hline & $b$ & $S E$ & $t$ & $95 \% \mathrm{CI}$ & $b$ & $S E$ & $t$ & $95 \% \mathrm{CI}$ & $b$ & $S E$ & $t$ & $95 \% \mathrm{CI}$ \\
\hline Constant & 4.34 & 0.25 & $17.6^{* * *}$ & $3.85,4.83$ & .39 & 0.03 & $13.31 * * *$ & $.34, .45$ & 29.35 & 2.77 & $10.60 * * *$ & $23.88,34.82$ \\
\hline Social ideology & .74 & 0.2 & $3.72 * * *$ & $.35,1.13$ & .05 & 0.02 & $2.47^{*}$ & $.01, .09$ & -1.2 & 2.23 & -0.54 & $-5.61,3.20$ \\
\hline Economic ideology & -0.31 & 0.22 & -1.4 & $-.74, .13$ & -0.02 & 0.02 & -0.94 & $-.06, .02$ & 3.3 & 2.47 & 1.34 & $-1.57,8.18$ \\
\hline Orientation $(\mathrm{O})$ & -0.07 & 0.38 & -0.2 & $-.82, .68$ & 0.09 & 0.05 & 1.94 & $-.18, .01$ & -0.004 & 4.33 & -0.001 & $-8.56,8.56$ \\
\hline Dimension (D) & -.68 & 0.35 & $-1.93 * *$ & $-1.37,01$ & -0.08 & 0.04 & -2.01 & $-.16, .01$ & -3.08 & 3.99 & -0.77 & $-10.97,4.81$ \\
\hline Social X O & -1.63 & 0.32 & $-5.14 * * *$ & $-2.26,-1.01$ & -.14 & 0.03 & $-4.55 * * *$ & $-.21,-.08$ & -5.77 & 3.59 & -1.61 & $-12.87,1.33$ \\
\hline Economic X O & 0.45 & 0.34 & 1.31 & $-.23,1.12$ & .07 & 0.04 & $2.1 *$ & $.01, .14$ & 1.14 & 3.85 & 0.3 & $-6.47,8.75$ \\
\hline Social X D & -0.5 & 0.31 & -1.6 & $-1.12, .12$ & -0.04 & 0.03 & -1.33 & $-.10, .02$ & -3.43 & 3.59 & -0.96 & $-10.52,3.66$ \\
\hline Economic X D & .65 & 0.32 & $2.03 *$ & $.02,1.29$ & 0.04 & 0.03 & 1.18 & $-.03, .10$ & 1.02 & 3.65 & 0.28 & $-6.18,8.22$ \\
\hline Social X Economic & 0.09 & 0.11 & 0.85 & $-.12, .30$ & 0.01 & 0.01 & 1.18 & $-.01, .03$ & 2.89 & 1.19 & $2.43^{*}$ & $.54,5.24$ \\
\hline $\mathrm{O} \times \mathrm{D}$ & 0.001 & 0.46 & 0.001 & $-.92, .92$ & .14 & 0.05 & $2.65^{* *}$ & $.04, .25$ & 1.2 & 5.27 & 0.23 & $-9.21,11.61$ \\
\hline Social X O X D & 1.20 & 0.45 & $2.7 * *$ & $.32,2.09$ & .14 & 0.04 & $3.2 * *$ & $.05, .23$ & 9.16 & 5.08 & $1.80 \dagger$ & $-.88,19.20$ \\
\hline Economic X O X D & -0.66 & 0.48 & -1.37 & $-1.60, .29$ & -.10 & 0.05 & $-2.22 *$ & $-.20,-.01$ & -10.54 & 5.41 & $-1.95 \dagger$ & $-21.24, .15$ \\
\hline Social X Economic X O & 0.18 & 0.14 & 1.36 & $-.08, .45$ & 0.01 & 0.08 & 0.28 & $-.02, .03$ & -1.42 & 1.54 & -0.92 & $-4.46,1.62$ \\
\hline Social X Economic X D & -0.1 & 0.13 & -0.74 & $-.35, .16$ & -0.01 & 0.07 & -1.77 & $-.05, .01$ & -1.23 & 1.47 & -0.84 & $-4.13,1.68$ \\
\hline
\end{tabular}

$* p<.05 ; * * p<.01 ; * * * p<.001$ 
Multi-Dimensional Ideological Conflict 75

Table 4

Study 5: moderated multiple regression analysis on worldview conflict and negative assessment (Step 3 only)

\begin{tabular}{|c|c|c|c|c|c|c|c|c|}
\hline & \multicolumn{2}{|c|}{ Worldviev } & \multicolumn{2}{|l|}{ Conflict } & \multicolumn{2}{|c|}{ Negative } & \multicolumn{2}{|l|}{ Assessment } \\
\hline & $b$ & $S E$ & $t$ & $95 \% \mathrm{CI}$ & $b$ & $S E$ & $t$ & $95 \% \mathrm{CI}$ \\
\hline Constant & 4.38 & 0.15 & $29.36 * * *$ & $4.09,4.68$ & 0.3 & 0.02 & $13.94 * * *$ & $.26, .34$ \\
\hline Social ideology & 4.75 & 0.62 & $7.69 * * *$ & $3.53,5.96$ & 0.36 & 0.09 & $4.11 * * *$ & $.19, .54$ \\
\hline Economic ideology & 1.97 & 0.68 & $2.91 * *$ & $.64,3.31$ & 0.08 & 0.1 & 0.77 & $-.12, .27$ \\
\hline Orientation $(\mathrm{O})$ & -0.22 & 0.21 & -1.05 & $-.62, .19$ & 0.05 & 0.03 & 1.56 & $-.1, .11$ \\
\hline Dimension (D) & -0.46 & 0.22 & $-2.139 *$ & $-.88,-.04$ & 0.01 & 0.03 & 0.46 & $-.05, .08$ \\
\hline Social X O & -8.74 & 0.88 & $-9.90 * * *$ & $-10.48,-7.01$ & -0.88 & 0.13 & $-6.98 * * *$ & $-1.13,-.64$ \\
\hline Economic X O & -4.04 & 0.93 & $-4.34 * * *$ & $-5.87,-2.21$ & -0.18 & 0.13 & -1.3 & $-.44, .09$ \\
\hline Social X D & -3.83 & 0.96 & $-3.98 * * *$ & $-5.73,-1.94$ & -0.32 & 0.13 & $-2.35^{*}$ & $-.59,-.05$ \\
\hline Economic X D & 1.88 & 1.01 & 1.87 & $-.10,3.87$ & 0.33 & 0.15 & $2.92 *$ & $.05,6.17$ \\
\hline Social X Economic & -0.57 & 1.73 & -0.33 & $-3.96,2.83$ & 0.53 & 0.26 & $2.07 *$ & $.03, .1 .03$ \\
\hline OX D & 0.30 & 0.28 & 1.06 & $-.25, .84$ & -0.07 & 0.04 & -1.73 & $-.15, .01$ \\
\hline Social X O X D & 4.63 & 1.32 & $3.52 * * *$ & $-2.05,7.22$ & 0.57 & 0.19 & $3.04 * *$ & $.20, .94$ \\
\hline Economic X O X D & -2.03 & 1.31 & -1.55 & $-4.59, .54$ & -0.31 & 0.19 & -1.64 & $-.67, .06$ \\
\hline Social X Economic X O & 1.59 & 2.08 & 0.76 & $-2.49,5.67$ & -0.26 & 0.3 & -0.85 & $-.85, .34$ \\
\hline Social X Economic X D & -0.51 & 2.09 & -0.24 & $-4.61,3.60$ & -0.17 & 0.3 & -0.55 & $-.76, .43$ \\
\hline
\end{tabular}

$* p<.05 ; * * p<.01 ; * * * p<.001$ 
Multi-Dimensional Ideological Conflict 76

Table 5

Study 5: Moderated multiple regression analysis on warmth traits, competence traits, and negative emotions (Step 3 only)

\begin{tabular}{|c|c|c|c|c|c|c|c|c|c|c|c|c|}
\hline & \multicolumn{4}{|c|}{ Warmth } & \multicolumn{4}{|c|}{ Competence } & \multicolumn{2}{|c|}{ Negative } & \multicolumn{2}{|l|}{ Emotion } \\
\hline & $b$ & $S E$ & $t$ & $95 \% \mathrm{CI}$ & $b$ & $S E$ & $t$ & $95 \% \mathrm{CI}$ & $b$ & $S E$ & $t$ & $95 \% \mathrm{CI}$ \\
\hline Constant & 6.69 & 0.18 & $37.03 * * *$ & $6.34,7.05$ & 7.71 & 0.16 & $49.25^{* * *}$ & $7.40,8.02$ & 0.22 & 0.02 & $10.25 * * *$ & $.18, .26$ \\
\hline Social ideology & -0.34 & 0.75 & -0.45 & $-1.81,1.13$ & 0.23 & 0.65 & 0.359 & $-1.04,1.50$ & 0.35 & 0.09 & $3.87 * * *$ & $.17, .52$ \\
\hline Economic ideology & -1.36 & 0.83 & -1.63 & $-2.99, .28$ & -1.30 & 0.71 & -1.82 & $-2.70,10$ & 0.04 & 0.10 & 0.40 & $-.16, .24$ \\
\hline Orientation $(\mathrm{O})$ & -0.49 & 0.25 & -1.948 & $-.98, .00$ & -0.68 & 0.22 & $-3.10 * * *$ & $-1.11,-.25$ & 0.01 & 0.03 & 0.16 & $-.05, .06$ \\
\hline Dimension (D) & -0.27 & 0.26 & -1.04 & $-.78, .24$ & -0.31 & 0.23 & -1.39 & $-.76, .13$ & -0.04 & 0.03 & -1.25 & $-.10, .02$ \\
\hline Social X O & 3.75 & 1.07 & $3.50 * *$ & $1.64,5.85$ & 3.03 & 0.94 & $3.23 * * *$ & $1.19,4.88$ & -0.78 & 0.13 & $-6.04 * * *$ & $-1.03,-.53$ \\
\hline Economic X O & 1.28 & 1.13 & 1.14 & $-.94,3.51$ & 1.87 & 0.98 & 1.90 & $-.06,3.80$ & -0.32 & 0.14 & $-2.34 *$ & $-.59,-.05$ \\
\hline Social X D & 1.20 & 1.17 & 1.03 & $-1.09,3.49$ & 0.92 & 1.03 & 0.90 & $-1.10,2.94$ & -0.26 & 0.14 & -1.86 & $-.54, .02$ \\
\hline Economic X D & -2.06 & 1.23 & -1.68 & $-4.48, .36$ & -2.36 & 1.07 & $-2.197 *$ & $-4.47,-.25$ & 0.25 & 0.15 & 1.67 & $-.04, .54$ \\
\hline Social X Economic & -4.59 & 2.13 & $-2.153^{*}$ & $-8.77,-.40$ & -4.33 & 1.82 & $-2.39 *$ & $-7.90,-.77$ & 0.25 & 0.26 & 0.97 & $-.26, .75$ \\
\hline OX D & 0.36 & 0.34 & 1.05 & $-.31,1.02$ & 0.55 & 0.29 & 1.87 & $-.03,1.13$ & -0.01 & 0.04 & -0.31 & $-.09, .07$ \\
\hline Social X O X D & -3.14 & 1.59 & $-1.969 *$ & $-6.27,-.01$ & -2.51 & 1.40 & -1.80 & $-5.27, .24$ & 0.52 & 0.19 & $2.67 *$ & $.14, .90$ \\
\hline Economic X O X D & 2.67 & 1.58 & 1.68 & $-.44,5.77$ & 1.51 & 1.39 & 1.09 & $-1.21,4.24$ & -0.13 & 0.19 & -0.68 & $-.51, .25$ \\
\hline Social X Economic X O & 3.80 & 2.53 & 1.50 & $-1.17,8.76$ & 5.04 & 2.20 & $2.30 *$ & $.73,9.35$ & -0.05 & 0.31 & -0.16 & $-.65, .56$ \\
\hline Social X Economic X D & 0.64 & 2.54 & 0.25 & $-4.34,5.63$ & 0.61 & 2.21 & 0.28 & $-3.73,4.95$ & 0.05 & 0.31 & 0.16 & $-.56,66$ \\
\hline
\end{tabular}

$* p<.05 ; * * p<.01 ; * * * p<.001$ 
Table 6

Support for the three hypotheses across Studies $1-5$

\begin{tabular}{llll}
\hline & Dimension-specific symmetry & Social primacy & Social-specific asymmetry \\
\cline { 2 - 3 } Study 1, sample 1 & Full support & No support & No support \\
Study 1, sample 2 & Mixed support & No support & No support \\
Study 1, sample 3 & Mixed support & No support & No support \\
Study 2, worldview conflict & Mixed support & Full support & No support \\
Study 2, prejudice & Mixed support & Full support & No support \\
Study 3, worldview conflict & Full support & Full support & No support \\
Study 3, explicit prejudice & Full support & Full support & No support \\
Study 3, implicit associations & Mixed support & Mixed support & No support \\
Study 4, worldview conflict & Mixed support & Mixed support & No support \\
Study 4, prejudice & Mixed support & No support & No support \\
Study 4, discrimination & Mixed support & No support & No support \\
Study 5, worldview conflict & Mixed support & Full support & No support \\
Study 5, negative assessment & Mixed support & Mixed support & No support \\
Study 5, political intolerance & No support & No support & No support \\
Study 5, warmth traits & Mixed support & Mixed support & No support \\
Study 5, competence traits & Mixed support & Mixed support & No support \\
Study 5, negative traits & No support & No support & No support \\
Study 5, negative emotions & Mixed support & Full support & No support \\
Study 5, anxiety-fear/envy-guilt & No support & No support & No support \\
Study 5, sympathy-pity & No support & No support & No support \\
Study 5, positive emotions & No support & No support & No support \\
\hline & & & \\
\hline
\end{tabular}

Note: Full support relies on all slopes being significant, as well as differences at 1 SD above and below midpoint. Mixed support indicates that some slopes were significant, but others were not, or that some differences at $1 \mathrm{SD}$ above and below the midpoint were significant, but that others were not. 
Figure 1

Hypotheses for the effects of social and economic ideology on prejudice

Panel A: dimension-specific symmetry hypothesis
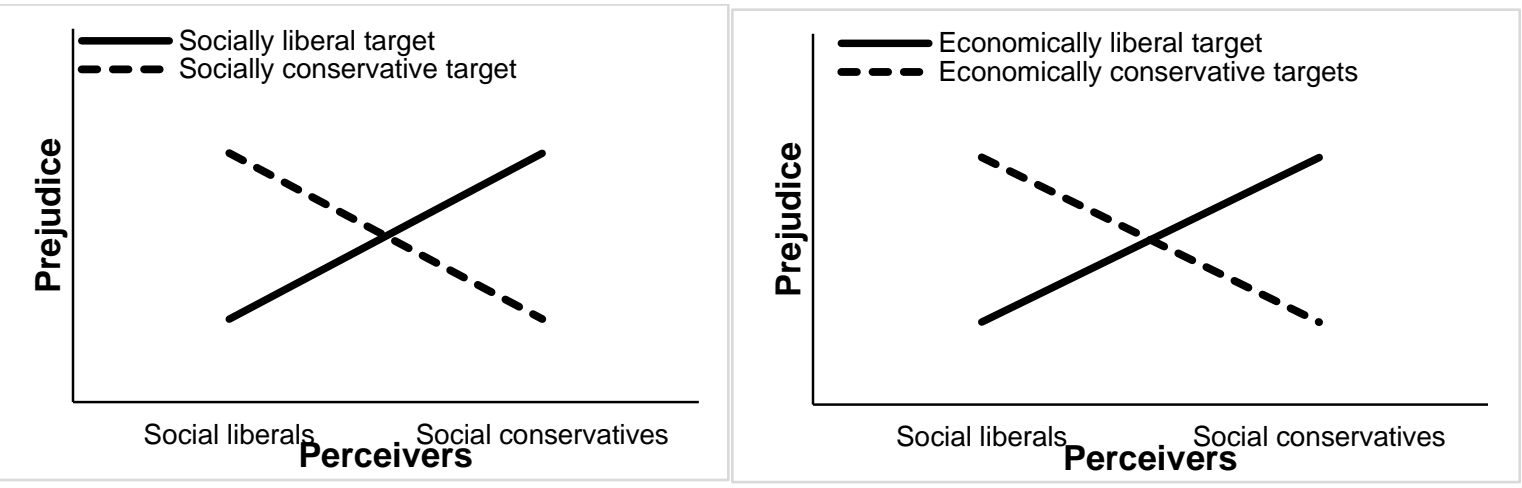

Panel B: social primacy hypothesis
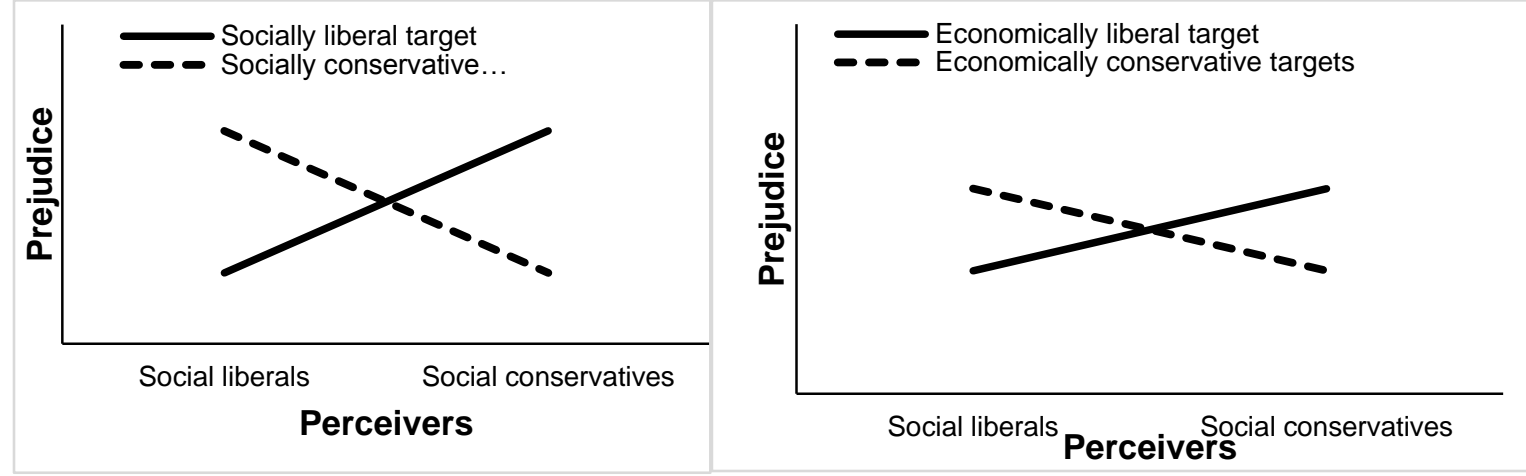

Panel C: social-specific asymmetry hypothesis

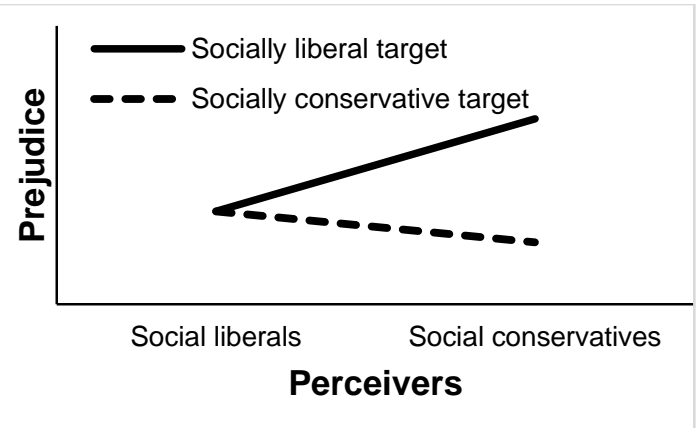

Hypothesis is agnostic about the economic dimension (see main text) 
Figure 2

Study 1: Interaction effects in Sample 1
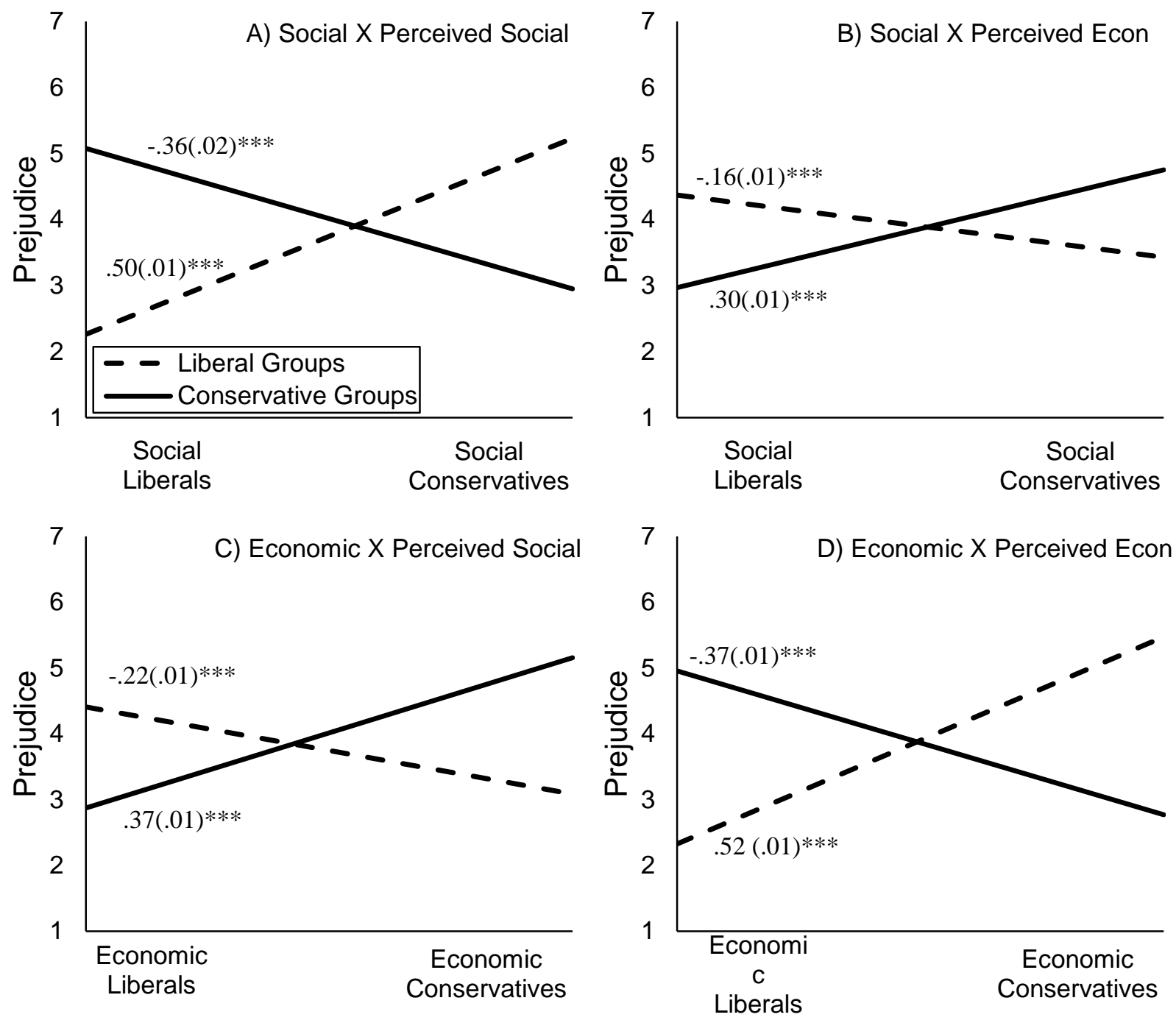
Figure 3

Study 2: Moderated multiple regression results for worldview conflict
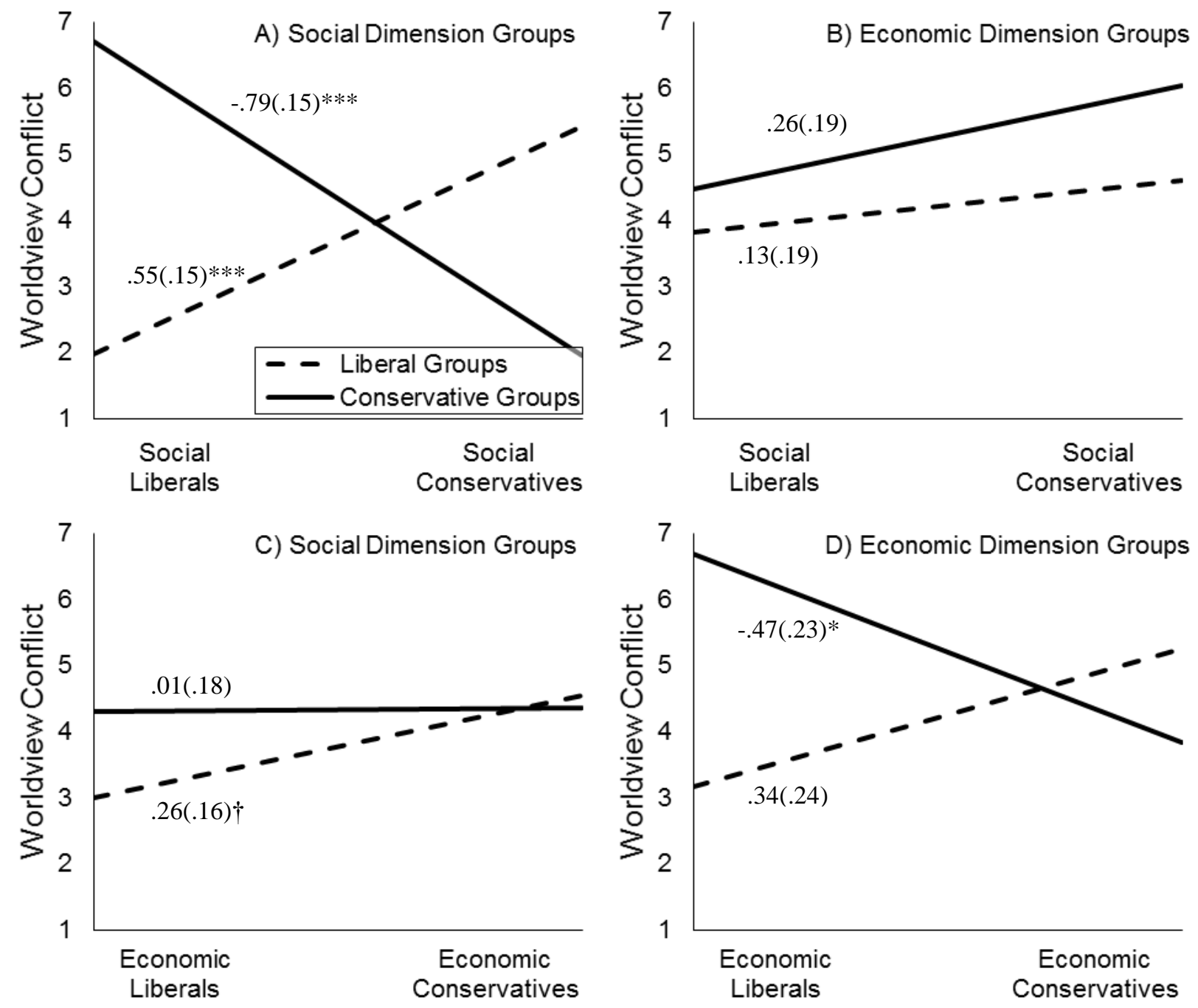

$\dagger p<.10 ; * p<.05 ; * * * \mathrm{p}<.001$

Note: Values in figures are unstandardized regression coefficients and standard errors (in parentheses). 
Figure 4

Study 2: Moderated multiple regression results for prejudice
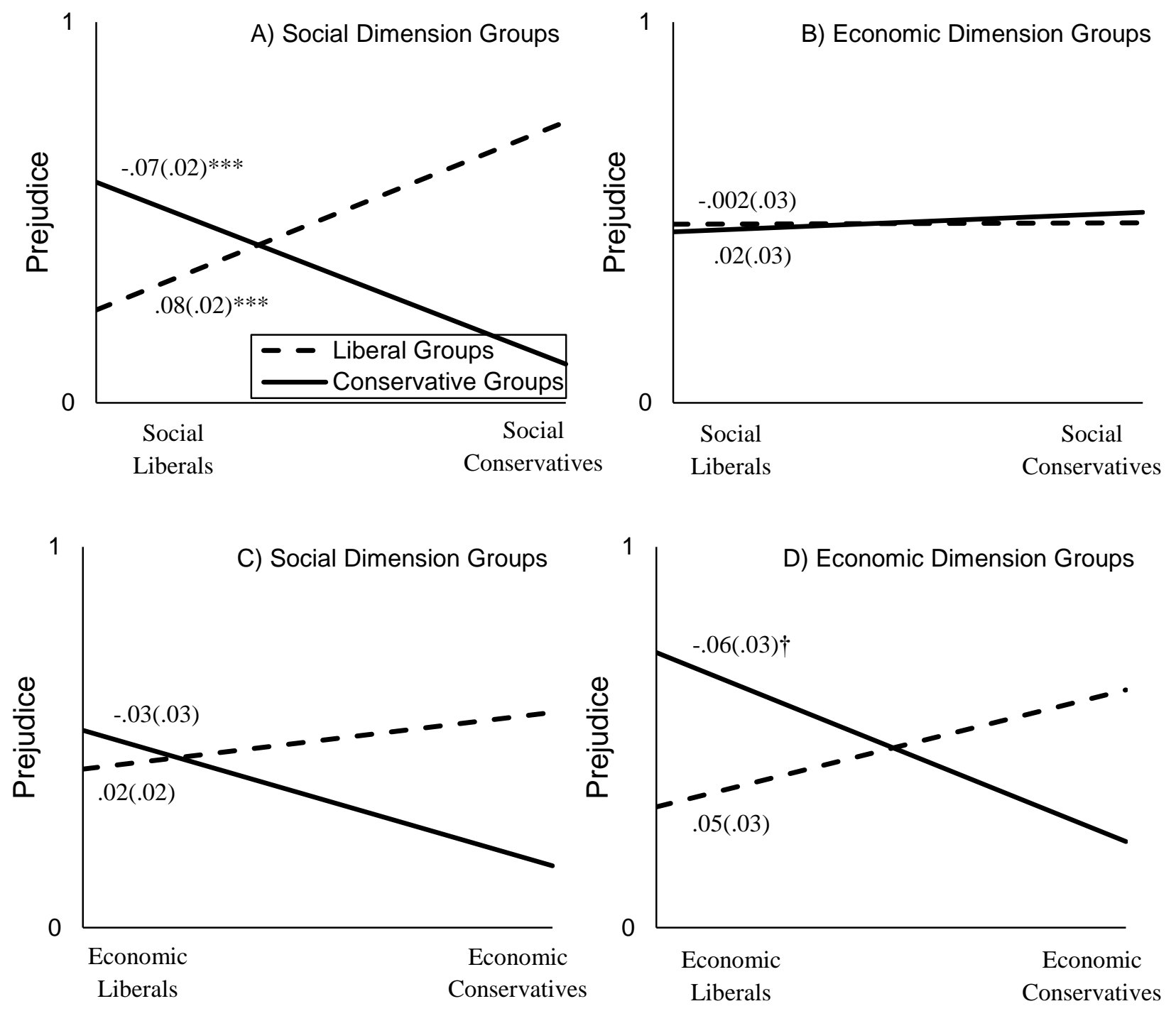

$\dagger p<.10 ; * * * p<.001$

Note: Values in figures are unstandardized regression coefficients and standard errors (in parentheses). 
Figure 5

Study 4: Moderated multiple regression results for worldview conflict
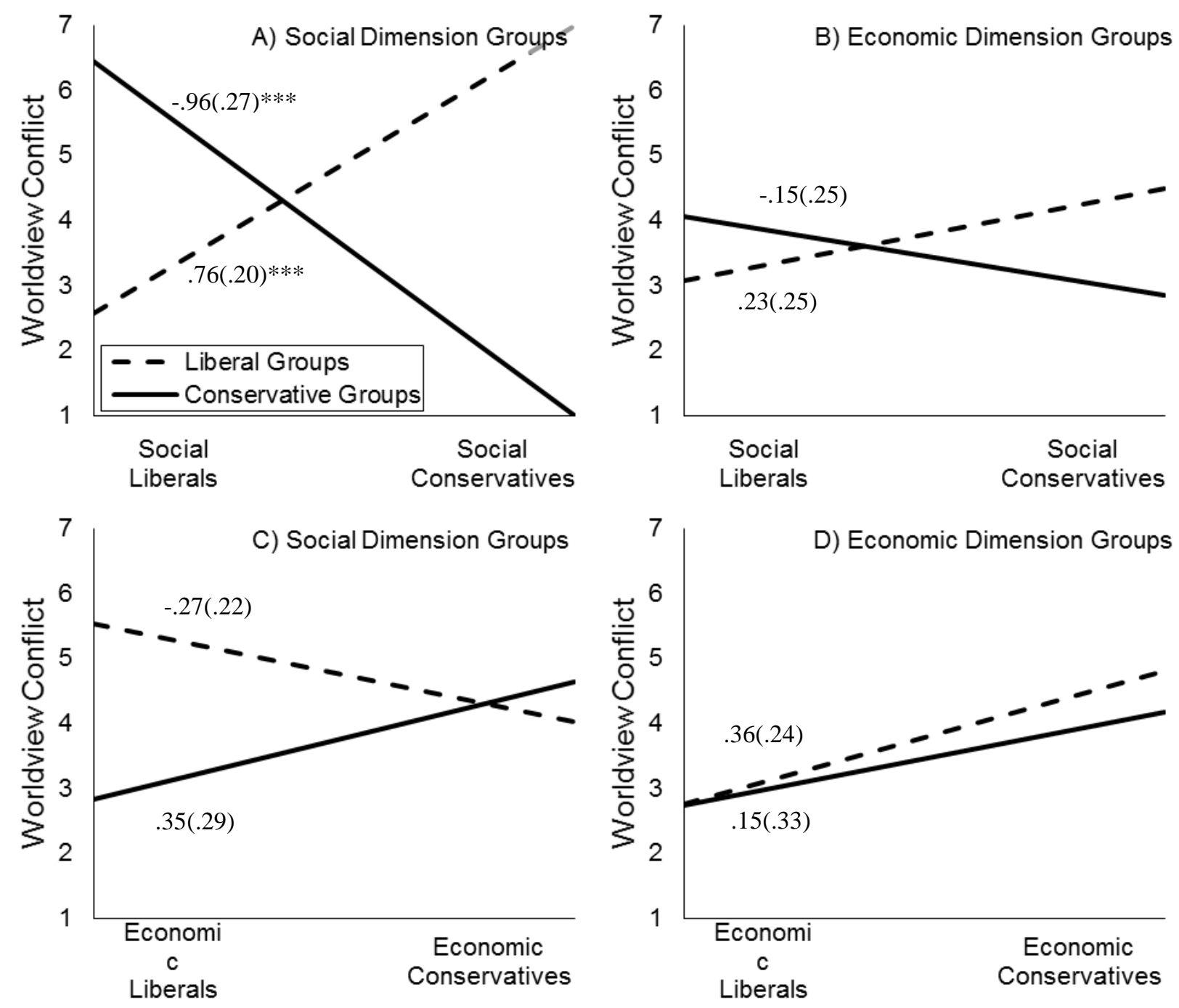

$* * * \mathrm{p}<.001$

Note: Values in figures are unstandardized regression coefficients and standard errors (in parentheses). 
Figure 6

Study 4: Moderated multiple regression results for prejudice
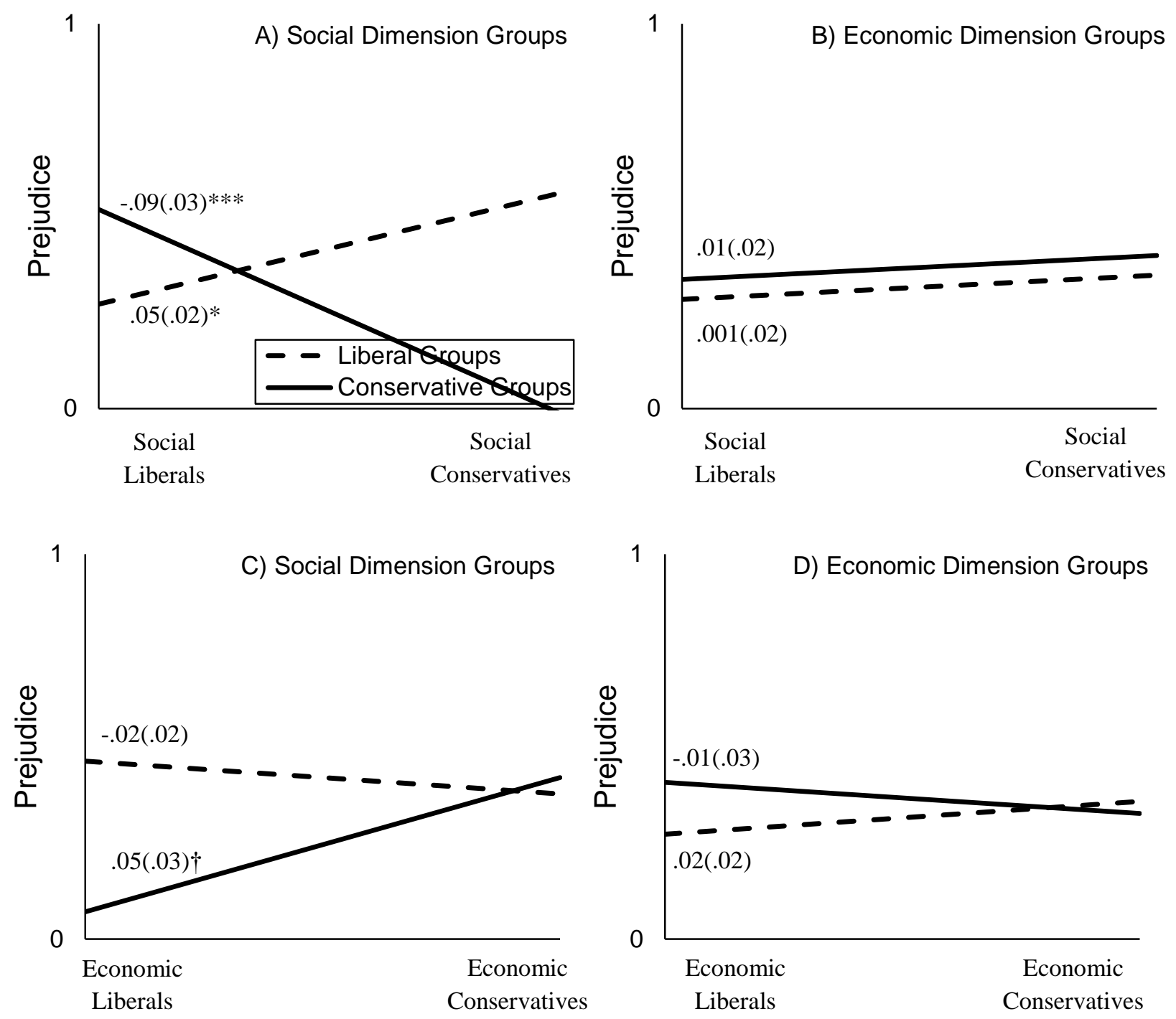

$\dagger p<.10 ; * p<.05 ; * * * p<.001$

Note: Values in figures are unstandardized regression coefficients and standard errors (in parentheses). 
Figure 7

Study 4: Moderated multiple regression results for ticket allocation to self
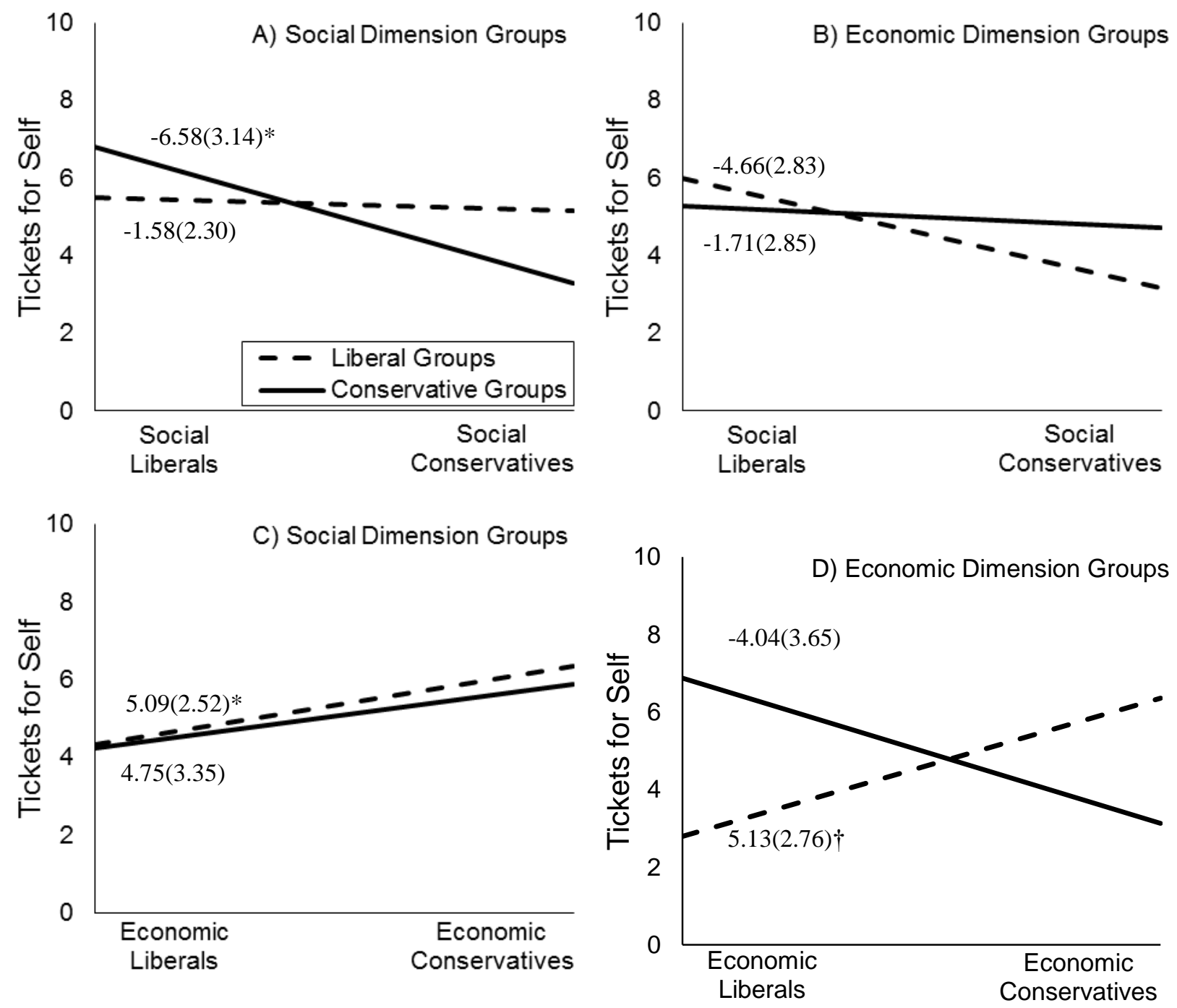

$\dagger p<.10 ; * p<.05$

Note: Values in figures are unstandardized regression coefficients and standard errors (in parentheses). 
Figure 8

Study 5: Moderated multiple regression results for worldview conflict
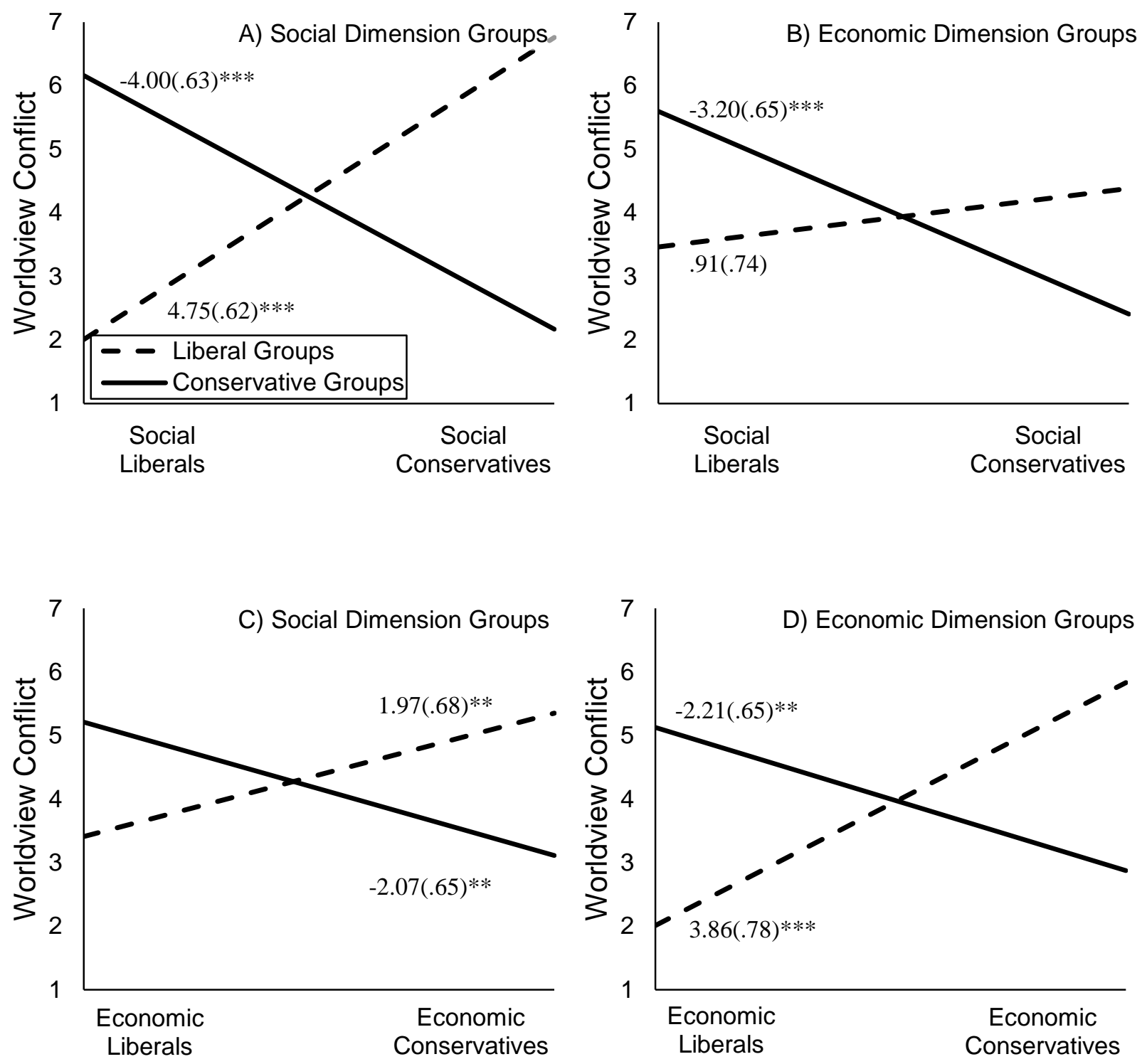

$* * p<.01 ; * * * p<.001$

Note: Values in figures are unstandardized regression coefficients and standard errors (in parentheses). 
Figure 9

Study 5: Moderated multiple regression results for overall negative assessment
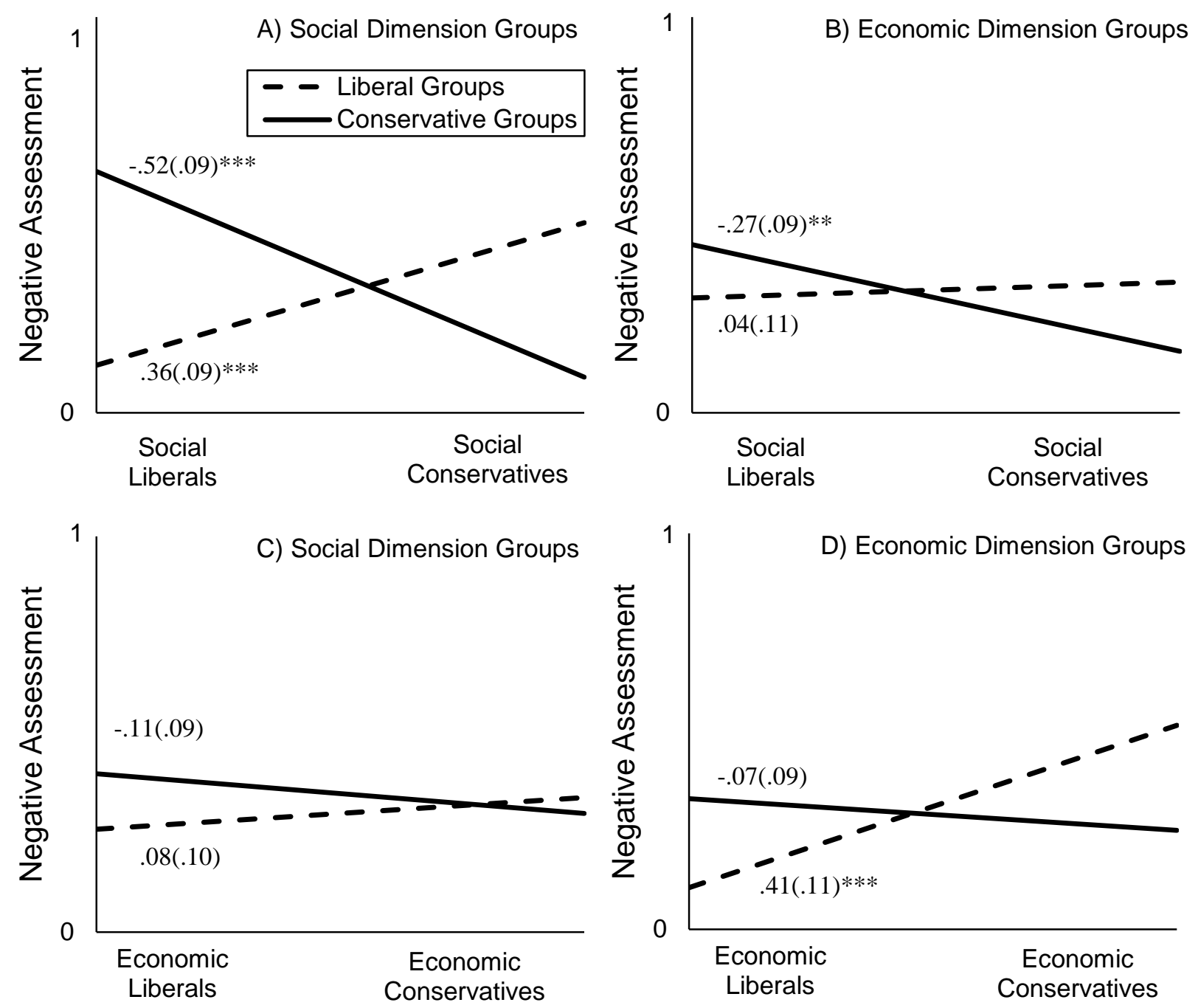

$* * p<.01 ; * * * p<.001$

Note: Values in figures are unstandardized regression coefficients and standard errors (in parentheses). 
Figure 10

Study 5: Moderated multiple regression results for warmth traits
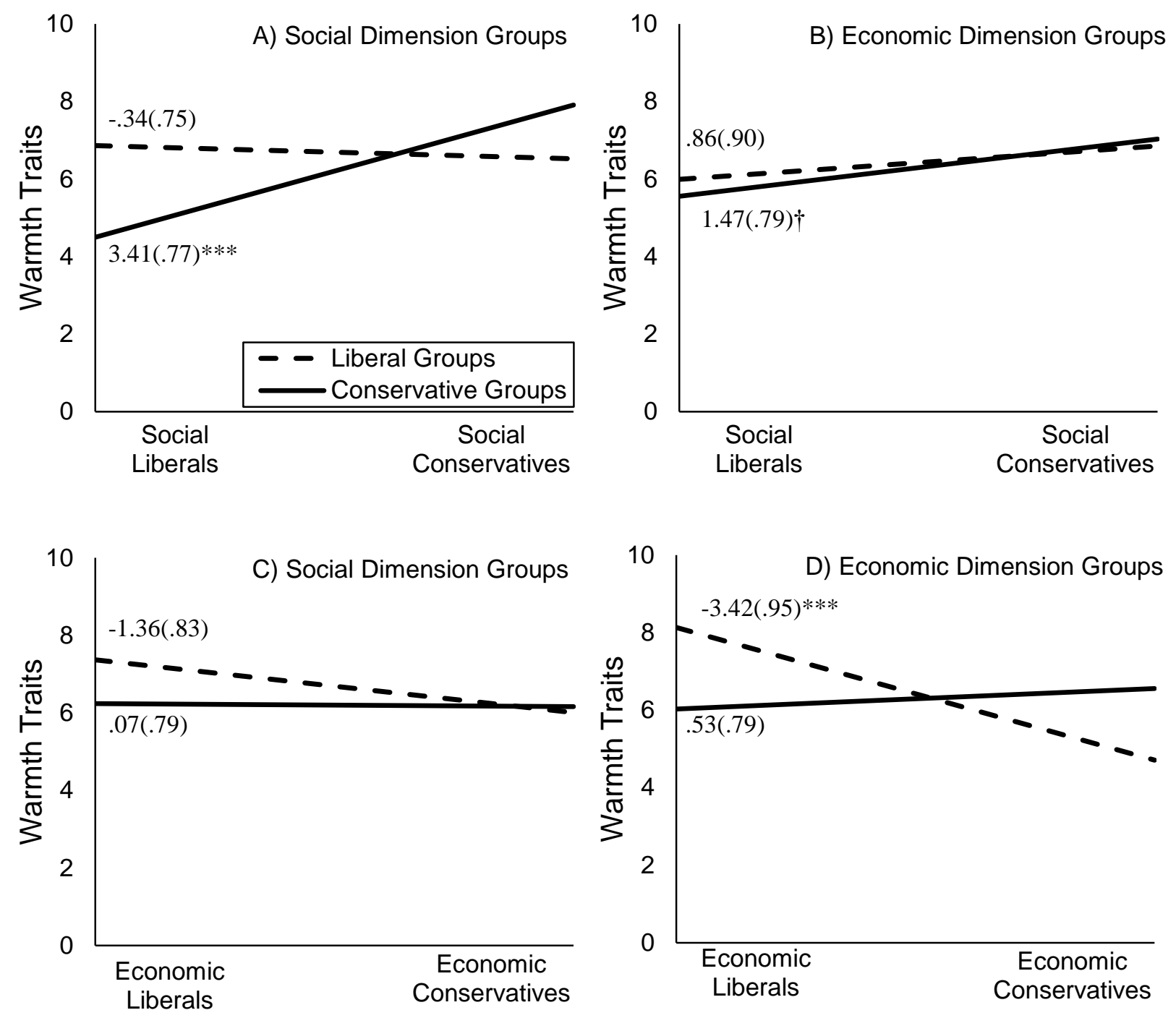

$\dagger p<.10 ; * * * p<.001$

Note: Values in figures are unstandardized regression coefficients and standard errors (in parentheses). 
Figure 11

Study 5: Moderated multiple regression results for competence traits
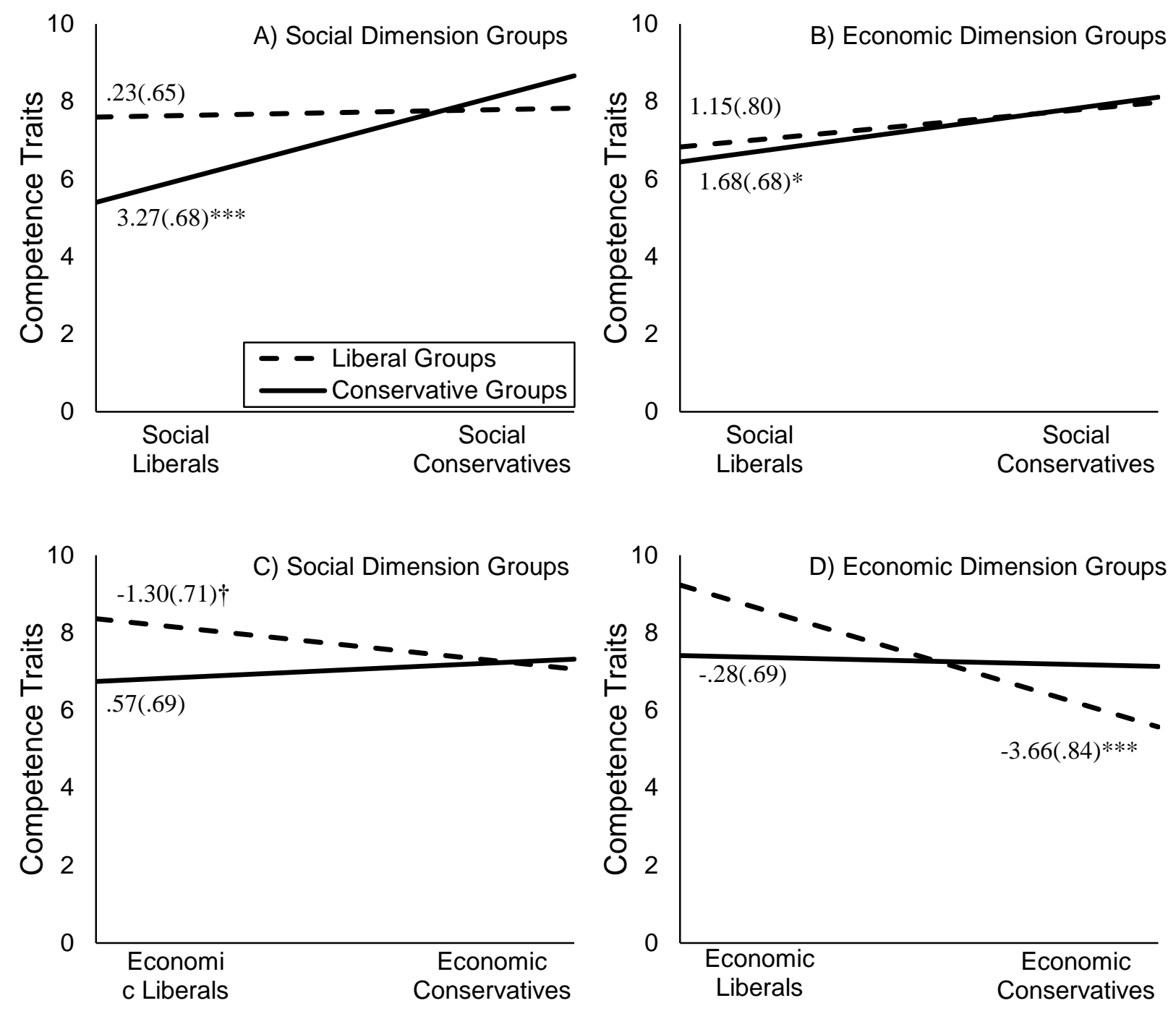

$\dagger p<.10 ; * p<.05 ; * * * p<.001$

Note: Values in figures are unstandardized regression coefficients and standard errors (in parentheses). 
Figure 12

Study 5: Moderated multiple regression results for negative emotions
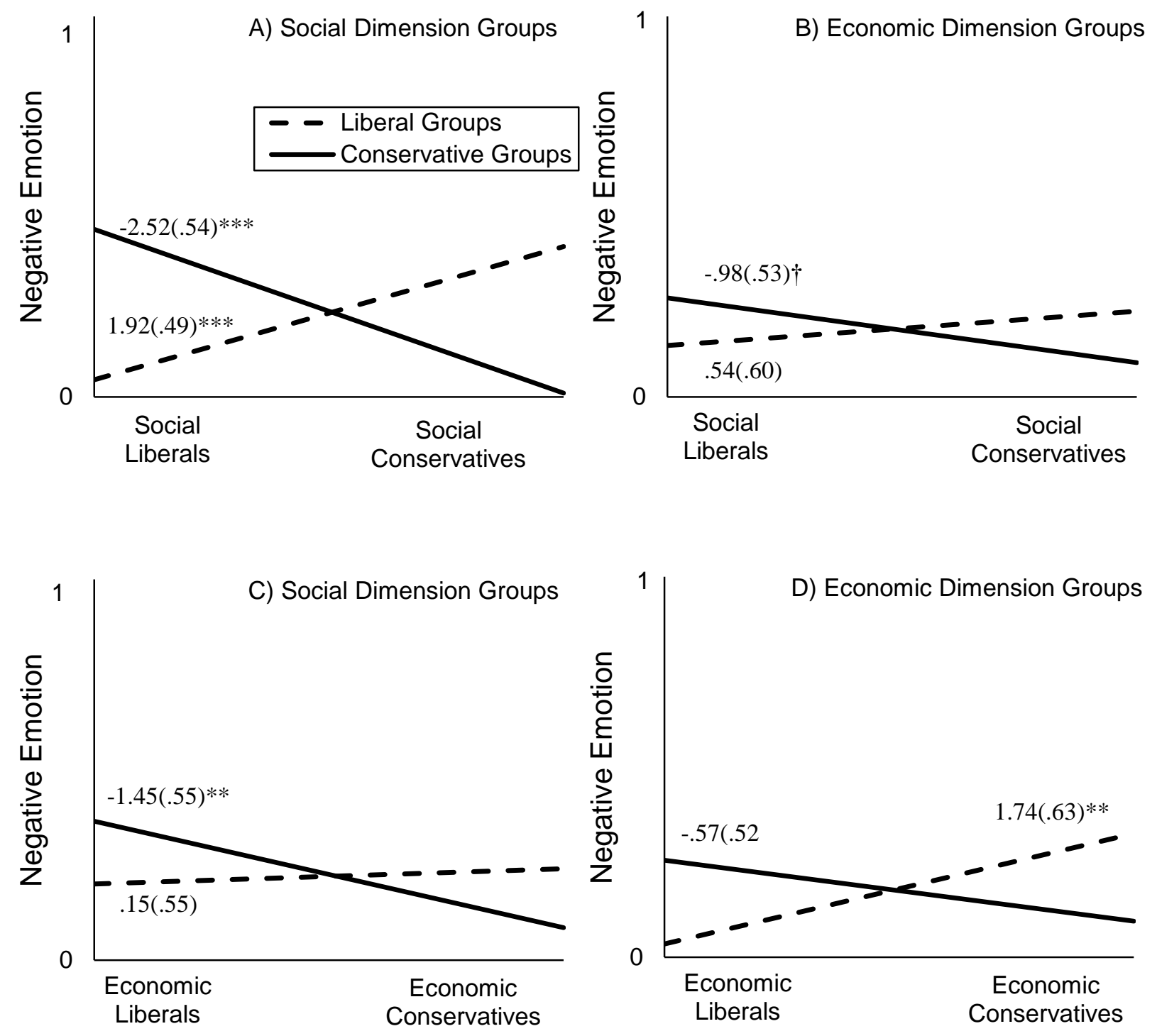

$\dagger p<.10 ; * p<.05$

Note: Values in figures are unstandardized regression coefficients and standard errors (in parentheses). Note that this is the log-transformed version of the negative emotions measure. 